\title{
Which approach to accounting for employee stock options best reflects market pricing?
}

\author{
Wayne R. Landsman $\cdot$ Ken V. Peasnell · \\ Peter F. Pope $\cdot$ Shu Yeh
}

Published online: 10 June 2006

(C) Springer Science+Business Media, LLC 2006

\begin{abstract}
We use a residual income valuation framework to compare equity valuation implications of four approaches to employee stock options (ESOs) accounting: $A P B 25$ "recognize nothing", SFAS 123 (revised) "recognize ESO expense", FASB Exposure Draft "recognize and expense ESO asset" and "recognize ESO asset and liability". Theoretical analysis shows only grant date recognition of an asset and liability, and subsequent marking-to-market of the liability, results in accounting numbers that capture the dilution effects of ESOs on current shareholder value. Out-of-sample equity market value prediction tests and in-sample comparisons of model explanatory power also support the "recognize ESO asset and liability" method.
\end{abstract}

Keywords Equity valuation - Employee stock options - ESO asset and liability $\cdot$ ESO expense $\cdot$ Residual income $\cdot$ Mark-to-market

\section{JEL Classification $\quad M 41 \cdot G 14$}

\footnotetext{
W. R. Landsman ( $ه)$

Kenan-Flagler Business School, University of North Carolina at Chapel Hill, Chapel Hill, NC 27599, USA

e-mail: wayne_landsman@unc.edu

K. V. Peasnell · P. F. Pope

The Management School, Lancaster University, Lancaster LA1 4YX, UK

e-mail: k.peasnel@lancaster.ac.uk

P. F. Pope

e-mail: p.pope@lancaster.ac.uk

S. Yeh

Department of Accounting, National Taiwan University, Taipei, Taiwan, ROC

e-mail: shuyeh@ntu.edu.tw
} 
The policy debate over how firms should account for employee stock options (ESOs) has been long and acrimonious. It focuses on whether it is appropriate to recognize ESO-related expense and mark-to-market gains and losses in the income statement, and ESO-related equity or liabilities and assets in the balance sheet. Recent empirical research provides some insights relevant to these questions. For example, Kirschenheiter, Mathur, and Thomas (2004, 2005) and Core, Guay, and Kothari (2002) report evidence on the importance of accounting for dilution effects in equity valuation; Hanlon, Rajgopal, and Shevlin (2003) shows that stock options are associated with future earnings growth; Bell, Landsman, Miller, and Yeh (2002), for a sample of profitable software companies, shows that the market appears to value their equity as if option grants create an intangible asset; and Aboody, Barth, and Kaznik (2004) shows the market prices ESO amortization as an expense after including controls for earnings growth.

We contribute to this literature in two main ways. First, we build on theoretical work by Christensen and Feltham (2003) and identify the properties of valuation estimates obtained using financial statement numbers from four ESO accounting methods that are central to the policy debate as inputs to the residual income valuation model. This analysis demonstrates the importance of recognizing both income statement and balance sheet effects of ESOs from a "super clean surplus" perspective, if the objective of financial statements is to provide information relevant to valuing existing equity shares. The accounting method most consistent with the super clean surplus perspective is that which includes an ESO asset and liability on the balance sheet and markto-market gains and losses on the liability in income. Second, for a sample of US firms, we examine the empirical relation between stock prices and estimated financial statement numbers under the four accounting methods. The empirical analysis suggests the accounting method most consistent with the stock market valuation of companies is again that which includes the ESO asset and liability on the balance sheet and mark-to-market gains and losses on the liability in income. Overall, our results suggest that currently mandated financial reporting standards provide incomplete information for existing shareholders.

We start with a model that captures key features of ESO transactions but is simple enough to show how financial statement numbers from four different ESO accounting methods might be used in an accounting-based valuation model. Our analysis draws on Feltham (1995), who uses the residual income valuation model (RIV) to demonstrate the importance of clarity over the claimants to be viewed as equity holders when there are outstanding contingent equity claims. ${ }^{1}$ The main objective of our analysis is to identify the consequences for equity valuation of using financial statement numbers from the different ESO accounting methods as RIV inputs. These effects are left implicit in Feltham (1995) and Christensen and Feltham (2003). In particular, we are interested in the extent to which the alternative methods account

${ }^{1}$ For a published version of the results, see Christensen and Feltham (2003, ch. 9). 
successfully for the economic dilution effects of ESOs on current shareholder equity value. The accounting methods we consider are (i) the intrinsic value approach, which we call the $A P B 25$ approach; (ii) the recognition of ESO expense, which we call the SFAS 123 (revised) approach; (iii) the recognition of an asset and its subsequent amortization as ESO expense, which we call the Exposure Draft approach, and (iv) the recognition of an ESO asset, its subsequent amortization as ESO expense and the recognition and marking-tomarket of an ESO liability, which we call the Asset and Liability approach.

Consistent with Feltham (1995) and Christensen and Feltham (2003), our analysis indicates that of the four accounting methods considered, only the Asset and Liability approach results in recognized book equity and net income numbers that result in correct identification of the economic dilution effects of ESOs. This is because it is the only method that applies what Christensen and Feltham refer to as "super clean surplus accounting", whereby income reflects all gains and losses attributable to existing shareholders. Our analysis also shows that use of book equity and net income numbers from the $A P B 25$ and Exposure Draft methods results in overestimates of the value of current shareholder equity. Specifically, these two approaches yield book equity and net income numbers that, when used as inputs to RIV, result in a valuation estimate equal to the sum of current equity value and ESO value. Both methods satisfy "clean surplus" in that all gains and losses arising from transactions not involving equity claimants pass through income. However, neither method accounts for ESO dilution effects for the purposes of estimating the value of current equity claims. Christensen and Feltham label these methods as "mixed surplus" accounting methods because the accounting numbers are related to the value of the aggregate claims of both existing and potential future equity holders.

Our analysis yields an important new insight. We find that the SFAS 123 (revised) approach results in book equity and net income numbers that, when used in RIV, also lead to overstatement of current equity value. However, the degree of overstatement is lower than in the cases of the $A P B 25$ and Exposure Draft approaches. Estimated value based on SFAS 123 (revised) numbers equals the value of current equity plus a fraction of ESO value. The valuation estimate obtained under this accounting method is not easily interpretable. This is especially troubling because the SFAS 123 (revised) approach is the approach mandated by the two leading accounting standard setting bodies in the world, in the face of fierce opposition from much of the business community.

The second main contribution of this paper is the empirical examination of how well the four accounting methods reflect actual market pricing. We use publicly available data to estimate the values of book equity and residual income (and relevant components) that would be reported under each of the four accounting methods. ${ }^{2}$ Although the theoretical analysis assumes

\footnotetext{
2 The data needed for the $A P B 25$ and SFAS 123 (revised) approaches are readily available from SFAS 123 mandated disclosures, whereas the additional items needed to implement the Exposure Draft and particularly the Asset and Liability approaches have to be approximated by the external analyst, with attendant greater risks of measurement errors.
} 
complete information of the expected future residual income stream, our empirical analysis adopts the assumption that the only information available for a given accounting method is current equity book value and current residual income (or components thereof). We then estimate regressions of observed equity values on equity book value and current residual income (and components) for each accounting method. The accounting method that best reflects the market's implied view of the economic substance of ESOs will yield the accounting numbers that best explain market value of equity.

To identify the accounting method that best explains market value of equity, we employ both out-of-sample and in-sample tests, based on S\&P 500 firms with available data from 1997 to 2001. The out-of-sample tests compare contemporaneous equity market value predictions based on each of the four methods. The in-sample tests involve comparisons of model-explanatory power from two versions of estimating equations relating to each of the four accounting methods. The first set of models includes residual income and equity book value applicable to a given method, and the second set also includes option fair value as an explanatory variable with its coefficient restricted to equal minus one. A comparison of these two nested models is equivalent to testing whether the appropriate value construct explained by the accounting items is the total value of all equity claims or the value of existing equity claims alone. We also compare the relative explanatory power of models based on the different accounting methods.

We conduct our out-of-sample tests by estimating jack-knife regressions including accounting amounts applicable to each of the four accounting methods. The jack-knifing procedure generates firm-specific equity market value predictions using regression coefficients estimated with data for all sample firms except the firm under consideration. We compare the accuracy of equity value predictions across the four accounting methods using the meansquare and mean-absolute error metrics, and by examining the relative frequency with which each method yields the lowest prediction errors. Based on the theoretical modeling, we expect the lowest prediction errors for the Asset and Liability method, highest prediction errors for the APB 25 and Exposure Draft methods, and prediction errors between the two extremes for the $S F A S$ 123 (revised) method. A different, empirically grounded expectation is that out-of-sample equity market value predictions will improve as more information is provided about ESOs. We exploit this alternative by developing and testing a model that combines all of the ESO-based residual income and equity book value components from the four accounting methods. Our empirical prediction is that the Asset and Liability method will have the lowest prediction errors, followed by the Exposure Draft method, the SFAS 123 (revised) method, and the $A P B 25$ method. The empirical evidence is mostly consistent with these latter empirical predictions.

We conduct our in-sample tests using the finding from our theoretical analysis that equity book value and residual income explain the value of total equity claims, i.e. current equity value plus ESO fair value, for the $A P B 25$ and Exposure Draft methods, whereas it is the current equity value that is 
explained by book value and residual income for the Asset and Liability method. Our theory provides no clear prediction for the SFAS 123 (revised) method. We test these predictions by estimating four pairs of regressions (one pair for each accounting method), where the dependent variable is current equity value and the common regressors are book equity and residual income estimated for the respective accounting method. The second regression for each method also includes ESO fair value as a regressor, with its coefficient restricted to equal minus one. We compare the relative explanatory power of the two regressions for each method. Findings from these tests are largely consistent with our theoretical predictions. Also, consistent with our predictions and the out-of-sample test findings, the Exposure Draft and Asset and Liability valuation models are better specified than those based on the SFAS 123 (revised) method.

The remainder of this paper is organized as follows. Section 1 presents analysis of how the four different approaches to accounting for ESOs affect the relation between market values and future accounting numbers. Section 2 describes the empirical estimating equations. Section 3 describes the sample and data. Section 4 presents the empirical findings. Finally, Section 5 summarizes and concludes the study.

\section{Theoretical analysis}

\subsection{Conceptual issues in ESO accounting}

Our theoretical and empirical analysis considers four main ESO accounting approaches. For many years, reporting in the U.S. was governed by Accounting Principles Board Opinion 25: Accounting for Stock Issued to Employees (AICPA, 1972, hereafter APB 25). APB 25 allowed firms to avoid recognizing employee stock compensation expense if the options that were granted had a zero intrinsic value at the date of grant. Subsequently, Statement of Financial Accounting Standards No. 123: Accounting for Stock-Based Compensation (FASB, 1995, hereafter, SFAS 123) required firms to disclose in footnotes to the financial statements the pro forma effects on earnings of employee compensation expense attributable to amortizing the fair value of employee stock options at the grant date, but it continued to permit firms to follow $A P B 25$ in valuing options granted at their (usually zero) intrinsic values and hence to avoid expense recognition. If firms had been required to recognize ESO expense based on fair value of ESO grants, Credit Suisse First Boston (2004a) reports that for S\&P 500 firms diluted EPS would have been 8 , 19 and $20 \%$ lower than reported EPS in 2003, 2002, and 2001, respectively. The sheer magnitude of this effect on income, as well as controversy over corporate managers cashing in ESOs before large price declines, raised the question of whether firms should be required to recognize ESO expense to ensure that investors get a more complete picture of corporate performance and underlying management compensation costs (e.g., Stiglitz, 2003, ch. 5). 
The pressure on the FASB in the U.S. to revisit SFAS 123 and to consider mandating recognition of ESO expense in income has been largely driven by the International Accounting Standards Board (IASB), which issued in February 2004 International Financial Reporting Standard No. 2, Share Based Payment (IASB, 2004). IFRS 2 requires income statement recognition of an ESO expense using grant date fair value. ${ }^{3}$ All adopters of IFRSs (e.g., all European Union firms beginning in 2005) are required to expense ESOs using grant date fair value. One month after passage of IFRS 2, the FASB issued an Exposure Draft, Share Based Payment (FASB, 2004a), the requirements of which closely parallel the international standard. The Exposure Draft was enacted as a standard in December 2004 as a revision of SFAS 123 (FASB, 2004b, hereafter SFAS 123 (revised)), and similar to IFRS 2 requires recognition of ESO expense using grant date fair value, beginning with financial statements released after December 15, 2005.

Corporate preparers, particularly those in high tech industries that use stock options as a major component of their compensation packages, are not keen on the requirement to expense ESOs. They raise two potentially valid criticisms. First, they argue that firms issue ESOs because they receive something in return. In other words, ESOs create an intangible asset, associated with improved employee incentives to increase future profitability, e.g. by creating intellectual capital. ${ }^{4}$ Neither SFAS 123 (revised) nor IFRS 2 recognizes this asset. The FASB acknowledged this issue in the exposure draft that preceded SFAS 123, Exposure Draft: Accounting for Stock-Based Compensation (FASB, 1993, hereafter, Exposure Draft). The Exposure Draft would have required employers to recognize as an intangible asset the fair value of stock options at the grant date, to amortize this asset, and to record the asset's amortization as employee compensation expense. In effect, SFAS 123 (revised) and IFRS 2 recognize an expense that relates to an off-balance sheet asset. This creates the impression that ESOs impose a cost without providing any compensating benefit to the firm. Critics contend that a more appropriate accounting treatment would be to recognize an asset at grant date, as is the case in the Exposure Draft.

Second, critics argue that the total compensation expense recognized using grant date ESO fair value may bear no relation to the net economic resources transferred to employees at exercise date, i.e. the difference between the cash proceeds, if any, and the cash the firm would receive if the shares were issued at market price. Conversely, if ESOs lapse unexercised, expense has been recognized under both SFAS 123 (revised) and IFRS 2, but no economic resources have been transferred to the employees. An accounting policy that (1) recognizes the firm's obligation to its employees as a liability at grant date, rather than as a component of equity, and (2) includes the effects of changes in

\footnotetext{
3 There are some minor differences between the accounting methods required to be used in income recognition by IFRS 2 and required to be used in the footnote disclosures under SFAS 123.

${ }^{4}$ Consistent with this, Hanlon et al. (2003) finds a positive empirical relation between ESO grants to the firm's top five executives and future earnings.
} 
the value of this liability post-grant date in income, would better capture the economic impact of ESOs on a firm's existing equity-holders. Although marking-to-market this obligation appears to be at odds with the ways in which most other liabilities are treated in financial statements, this is exactly the way both the IASB in IFRS 2 and FASB in the SFAS 123 (revised) treat the liability when ESO settlement takes the form of cash rather than the issuance of stock. It is also commonplace in accounting to regularly update the amounts shown for long-term liabilities, such as site restoration costs. Ohlson and Penman (2005) provides detailed arguments for why all financial claims based on the performance of a firm's stock price-ESOs, stock appreciation rights, put and call options, convertibles, warrants, and other hybrid securities-should be accounted for as marked-to-market liabilities.

These wider aspects of the wealth effects of ESOs have received relatively little attention in the literature. The policy focus has been on whether the issuance of ESOs gives rise to an expense that should be recognized in the financial statements. However, ESO issuances are transactions that raise fundamental questions as to whether there is an asset that should be recognized, whether the associated credits should be treated as equity items or as liabilities, and if the latter, whether updating adjustments to the liability should be viewed as gains or losses that belong in income. Central to this debate is the issue of whether accounting for dilutive securities such as ESOs should distinguish between current shareholders and potential future shareholders. One way of addressing this latter issue is to consider how the numbers produced under the different ways of accounting for ESOs best reflect their economic impact on the value a firm's equity. This is the focus of the present study.

\subsection{Accounting for ESOs}

Based on ESO accounting methods considered in the policy debate, we consider the following four approaches: ${ }^{5}$

1. Method 1: $A P B 25$ approach: recognize an expense equal to ESO intrinsic value at grant date, which is zero if ESOs are issued at-the-money. This approach effectively ignores ESOs until ESOs are exercised, when "paidin capital" is credited with the cash received.

2. Method 2: SFAS 123 (revised) approach: credit "paid-in capital-employee stock options" (PIC-options) as and when ESO expense is recognized. ${ }^{6}$ Add the balance on the PIC - options account to the cash received and include in paid-in capital as and when the option is exercised.

\footnotetext{
${ }_{5}^{5}$ Most ESOs are granted at-the-money. What follows ignores the issue of whether the options have an exercise price that is different to the market value of the underlying shares at grant date since incorporating this possibility merely complicates the analysis without adding anything significant.

${ }^{6}$ ESO expense is the annual amount needed to amortize the off-balance sheet fair valued ESO asset over the vesting period of the ESO.
} 
If the options are not exercised, leave the balance in PIC-options as a dirty surplus component of equity.

3. Method 3: 1993 FASB Exposure Draft approach: recognize an asset (prepaid compensation) at grant date equal to the fair value of the ESOs granted and amortize the asset over the vesting period as ESO expense. PIC-options is set equal to the value shown for the asset and left unchanged thereafter. As with the SFAS 123 (revised) method, the balance on PIC-options is added to the cash received and included in paid-in capital as and when the option is exercised and if not exercised left as a component of equity.

4. Method 4: Asset and Liability approach: as under method 3, recognize an asset and amortize it, but also recognize the fair value of the option as a liability and include subsequent gains and losses on marking-to-market of that liability in income. ${ }^{7}$ If the option is exercised, the value of the option plus the cash proceeds will equal the fair value of the equity issued to employees. If the option is not exercised, it will have been written down to zero. Either way, the liability will be extinguished.

Table 1 shows the accounting journal entries under each of the four methods. We use the following hypothetical example to illustrate the relevant entries. An ESO grant is made at time zero, entitling the employee to subscribe for ten shares in five years' time. ${ }^{8}$ The exercise price is fixed at the grant date share price of $\$ 40$ per share. The fair value of each option is estimated to be $\$ 10$ at grant date, giving a fair value of the option grant equal to $\$ 100$. ESO expense is determined by amortizing this estimate on a straight-line basis over five years at $\$ 20$ per annum. ${ }^{9}$ The fair value of each option increases to $\$ 22$ at the end of the first year and falls to $\$ 18$ at the end of the second year. After five years the firm's share price has increased to $\$ 55$, and so the fair value of each option at that point is equal to $\$ 55-40=\$ 15$.

Method 1 conforms to the "clean surplus" principle, since all recognized gains and losses pass through income. Method 4 shares this property. However, gain and loss recognition differs under the two methods. Method 1 is an example of what Christensen and Feltham (2003, ch. 9) label "mixed surplus" accounting, whereby gains and losses are accounted for from the perspective of the aggregate equity claims including existing and prospective equity holders. Method 4 is accounted for on what Christensen and Feltham call a

\footnotetext{
${ }^{7}$ A possible refinement to this procedure would be to follow the proposal by Ohlson and Penman (2005) that the change in option value be separated into an interest expense component and the residual component, in the expectation that the former is the predictable element and the other is the pure windfall.

${ }^{8}$ For simplicity, we ignore the possibility that the employee might exercise earlier as it makes no difference to the accounting.

${ }^{9}$ Again for simplicity, we ignore any tax implications.
} 
Table 1 Journal entries under alternative ESO accounting treatments ${ }^{a}$

Method 1: $A P B 25$

1. At time of granting the options

No entry required

2. Each year during the vesting period

No entry required

3. At exercise date

(1) If the options are exercised

Dr Cash

Cr Paid-in capital

To record receipt of cash

(2) If the options were to lapse unexercised

No entry required

Method 2: SFAS 123

1. At time of granting the options

No entry required

2. Each year during the vesting period

Dr ESO expense

Cr Paid-in capital—employee stock options

To record ESO expense

\section{At exercise date}

(1) If the options are exercised

Dr Cash

Dr Paid-in capital—employee stock options

Cr Paid-in capital

To record receipt of cash and close out PIC-options account

(2) If the options were to lapse unexercised

No entry required

Method 3: 1993 FASB Exposure Draft

1. At time of granting the options

Dr Pre-paid compensation expense

Cr Paid-in capital-employee stock options

To recognize fair value of ESO as an asset and as a component of equity

2. Each year during the vesting period

Dr ESO expense

Cr Pre-paid compensation expense

To record ESO expense

3. At exercise date

(1) If the options are exercised

Dr Cash

Dr Paid-in capital—employee stock options

Cr Paid-in capital

To record receipt of cash and close out PIC-options account

(2) If the options were to lapse unexercised

No entry required

Method 4: Asset and Liability Method

1. At time of granting the option

Dr Pre-paid compensation expense

Cr Obligation to issue shares to employees

To recognize fair value of ESO as an asset and as a liability

2. Each year during the vesting period

Dr ESO expense

Cr Pre-paid compensation expense

To record ESO expense 
Table 1 continued

In the case of the year 1 rise in the fair value of ESO options to $\$ 220$

Dr Loss on increase in value of ESO obligation

Cr Obligation to issue shares to employees

To mark-to-market the option liability and record loss

In the case of the year 2 fall in the fair value of ESO options to $\$ 180$

Dr Obligation to issue shares to employees

$\mathrm{Cr}$ Gain on decrease in value of ESO obligation

To mark-to-market the option liability and record a gain

3. At exercise date

(1) If the options are exercised

Dr Cash

Dr Obligation to issue shares to employees

Cr Paid-in capital

To record receipt of cash and cancel the option liability

(2) If the options were to lapse unexercised

Dr Obligation to issue shares to employees

Cr Gain on lapse of unexercised ESOs

To cancel the option liability and record a gain on the lapse of unexercised ESOs

\begin{abstract}
${ }^{\mathrm{a}}$ We use the following hypothetical example to illustrate the relevant entries. An ESO grant is made at time zero, entitling the employee to subscribe for ten shares in five years' time. The exercise price is fixed at the grant date share price of $\$ 40$ per share. The fair value of each option is estimated to be $\$ 10$ at grant date, giving a fair value of the option grant equal to $\$ 100$. ESO expense is determined by amortizing this estimate on a straight-line basis over five years at $\$ 20$ per annum. The fair value of each option increases to $\$ 22$ at the end of the first year and falls to $\$ 18$ at the end of the second year. After five years the firm's share price has increased to $\$ 55$, and so the fair value of each option at that point is equal to $\$ 55-$ $40=\$ 15$
\end{abstract}

"super-clean surplus" basis. Under this method, income reflects all gains and losses attributable only to existing shareholders. ${ }^{10}$

The accounting entries shown in Table 1 reveal that the four accounting methods can be thought of in hierarchical terms, as providing increasingly comprehensive measures of the wealth-creation (i.e., income statement) effects associated with the use of ESOs as a form of employee compensation. Method 1 effectively ignores ESOs, and as such it provides no measures of the effects when the ESO intrinsic value at grant date is zero. Methods 2 and 3 both recognize in net income the grant of the option as a form of compensation expense alongside cash wages, pension expense and other employee benefits. ${ }^{11}$ Methods 1,2 and 3 all adopt an entity perspective on the measurement of income, ignoring any gains and losses suffered by the current shareholders as the value of the ESOs change through time (Ohlson \& Penman, 2005). In contrast, Method 4 takes a proprietary perspective, including in

\footnotetext{
${ }^{10}$ Other academic researchers (Kirschenheiter et al., 2003, 2004; Ohlson \& Penman, 2005) and investment analysts (Credit Suisse First Boston, 2004b) make a related observation regarding Method 4's theoretical superiority regarding accounting ESO dilution to that provided by Christensen and Feltham (2003).

11 The difference between these two methods is not in the recognition of comprehensive income, but rather as shown in section 1.4, the different balance sheet treatment in Method 3 results in a measure of residual income that yields an interpretable residual income-based valuation estimate whereas Method 2 does not.
} 
comprehensive income the changes in value of the ESOs, in addition to the charge for ESO expense recognized under Methods 2 and $3 .^{12}$

We now develop a model showing the consequences of the alternative accounting treatments of ESOs and the related implications for accountingbased valuation.

\subsection{Model}

\subsubsection{Model setup}

Consider a firm that has granted an ESO to a manager at date 0 that is exercisable at date $T$ on payment of the exercise price, $X$. The manager owns no other stock or stock options. No further ESO contracts are expected to be granted in the future. ${ }^{13}$ At grant date 0 , the net incomes in future periods, $N I_{t}$, $t=1,2, \ldots$, are uncertain, but the market's net income forecasts incorporate the anticipated motivational and retention benefits that led the firm to choose the manager's compensation contract. Dividends in future periods will be shared between existing shareholders $(e)$ and the manager $(m)$ :

$$
d_{t}=d_{t}^{e}+d_{t}^{m}
$$

with the existing shareholders receiving $d_{t}^{e}$ dollars and the manager getting $d_{t}^{m}$ dollars. ${ }^{14}$ The dividend payouts will be according to their stock ownership at the time, which we can represent as the $n^{e}$ shares currently held by existing shareholders and the $n^{m}$ shares that the employees might obtain at a total cost to them of $X$. Thus $\left(d_{t}^{m} / d_{t}^{e}\right)=\left(n^{m} / n^{e}\right)$. Until date $T+1$, all the dividends flow to the existing shareholders, i.e., $d_{t}=d_{t}^{e}, t=1,2, \ldots, T$. If the ESO subsequently lapses unexercised, the manager gets nothing, i.e.,

\footnotetext{
${ }^{12}$ Ohlson and Penman (2005) recommends additional accounting entries for Method 4 beyond those set out in Table 1. As well as charging ESO expense to net income, the paper also charges against net income an imputed interest expense based on the beginning-of-period fair value of the ESOs. This interest expense is deducted from (added to) the loss (gain) from any increase (decrease) in the value of the ESOs during the period. That gain or loss is then included in other comprehensive income. The interest expense can be thought of as the predictable element in the change in the value of the ESOs and the remaining gain or loss as the unpredictable element. Ohlson and Penman (2005) also advocates "truing up" net income over time, either by transferring the accumulated gains and losses into net income at the end of the life of each option, or spreading the accumulated amounts into net income over time, thereby smoothing out items that have low persistence. We do not consider these refinements in our theoretical analysis because they do not change the valuations in our model.

13 We make this assumption to simplify the exposition. Since none of the accounting methods under consideration involves immediate recognition of options that might be granted in the future, nothing is gained by introducing such complications. We return to the valuation implications of this simplification at the end of Section "Dividend-based valuation".

${ }^{14}$ Note that our analysis is cast in terms of total dollar amounts rather than per share amounts. Our purpose in focusing on dollar amounts is primarily to avoid irrelevant complications such as the need to model the ESOs as warrants (Li \& Wong, 2005), and hence to sidestep the endogeneity problem arising from the mutual dependence, at the per share level, of stock and ESO values.
} 
$d_{t}^{m}=0, t=T+1, T+2, \ldots$ We assume that the value of the firm and the claims of $e$ and $m$ do not depend on the exercise price, $X .^{15}$ Cash flows and non-ESO components of accounting accruals are assumed to be unaffected by the choice of accounting treatment of the ESO. ${ }^{16}$

The manager's net ESO compensation at exercise date $T$ will be zero if the options lapse unexercised. On the other hand, if the options are exercised, the economic value of the manager's ESO compensation will equal the amount by which the current total market value of the $n^{m}$ shares received exceeds the amount $X$ paid to acquire them. We can write $m$ 's option exercise decision at time $T$ as

$$
\max \left(M V_{T}^{m}-X, 0\right)=M V_{T}^{m}-\min \left(M V_{T}^{m}, X\right),
$$

where the (currently uncertain) total market value of the $n^{m}$ shares that might be issued to $m$ at that date is

$$
M V_{T}^{m}=\sum_{t=T+1}^{\infty} \frac{E_{T}\left[d_{t}^{m}\right]}{(1+r)^{t-T}},
$$

where $E_{T}[$.$] is the expectations operator evaluated using risk-neutral proba-$ bilities based on information available at date $T$ and $r$ is the (assumed constant) risk-free rate of interest. The value of the ESO at grant date, $O P V_{0}$, can be expressed in terms of the discounted expected value of (2):

$$
\begin{aligned}
O P V_{0} & =\frac{E_{0}\left[M V_{T}^{m}-\min \left(M V_{T}^{m}, X\right)\right]}{(1+r)^{T}} \\
& =\frac{\int_{X}^{\infty} M V_{T}^{m} \mathrm{~d} F\left(M V_{T}^{m}\right)-X \int_{X}^{\infty} \mathrm{d} F\left(M V_{T}^{m}\right)}{(1+r)^{T}},
\end{aligned}
$$

where $F\left(M V_{T}^{m}\right)$ is the cumulative risk-neutral probability density function associated with $M V_{T}^{m}$. By the law of iterated expectations, we can use (3) to rewrite (4) as

$$
O P V_{0}=\sum_{t=T+1}^{\infty} \frac{E_{0}\left[d_{t}^{m}\right]}{(1+r)^{t}}-\frac{E_{0}[X]}{(1+r)^{T}}
$$

\footnotetext{
15 The exercise proceeds are a source of capital to the firm. To avoid irrelevant complications, we make the standard Miller and Modigliani (1961) type of assumption that the firm is following an optimal investment strategy such that an additional dollar of $X$ results in a dollar increase in dividends, leaving the total value of the firm unchanged. We make an equivalent assumption regarding $m$ 's employment contract. An increase in $X$ will result in the ESO being worth less to $m$, but we assume that this would be offset by an increase in straight salary such that both $m$ 's utility and the value of $e$ 's shares are unchanged.

${ }^{16}$ We make this assumption because, in practice, during our sample period, all sample firms use the APB 25 method. When we conduct our empirical tests, we impose the four ESO accounting methods on the data. It is therefore important that our theoretical analysis does not incorporate the effects of ESO accounting methods on managerial behavior.
} 
where $E_{0}[X]=X \int_{X}^{\infty} \mathrm{d} F\left(M V_{T}^{m}\right)$ is the exercise price multiplied by the probability of the option being exercised. As long as there is some probability that the option will be exercised, it follows from (2) that the ESO will have a strictly positive value, i.e., $O P V_{0}>0$.

\subsubsection{Dividend-based valuation}

The date 0 value of the existing shareholders' claim can be expressed as

$$
M V_{0}^{e}=\sum_{t=1}^{\infty} \frac{E_{0}\left[d_{t}^{e}\right]}{(1+r)^{t}} .
$$

Consistent with Christensen and Feltham (2003), expression (6) can be redefined, using (1) and (3), in terms of the aggregate dividend flow expected to accrue to both current and future shareholders, adjusted for the dilution effect associated with the ESO grant. The ESO will only be exercised by $m$ if $M V_{T}^{m}>X$ and the economic cost incurred by $e$ will exceed $X$, the cash proceeds received by the firm from the exercise of options. The correct dilution adjustment is the expected market value of the $n^{m}$ shares subsequently issued to $m$. This can be captured explicitly by writing $M V_{0}^{e}$ in terms of total dividends expected to be paid to $e$ and $m$, recognizing that the subsequent issuance of $n^{m}$ new shares to $m$ will dilute the claim of $e$ by an amount equal to the expected market value of those shares, i.e., by $E_{0}\left[M V_{T}^{m}\right]$ :

$$
M V_{0}^{e}=\sum_{t=1}^{\infty} \frac{E_{0}\left[d_{t}\right]}{(1+r)^{t}}-\frac{E_{0}\left[M V_{T}^{m}\right]}{(1+r)^{T}} .
$$

Value per share can then be computed by dividing $M V_{0}^{e}$ by $n^{e}$, the number of current shares outstanding, without any further adjustment for the dilution effects of the ESO.

A measure of equity value that "mixes" or "combines" the claims of existing and future shareholders, $M V_{0}^{c}$, can also be derived. This measure discounts the projected net dividend flow between the firm and all current and prospective equity claimants, treating new capital contributions as negative dividends:

$$
M V_{0}^{c}=\sum_{t=1}^{\infty} \frac{E_{0}\left[d_{t}\right]}{(1+r)^{t}}-\frac{E_{0}[X]}{(1+r)^{T}} .
$$

It follows from (1) and (5) that this combined value is equal to the sum of the market values of existing shares and the ESO:

$$
\begin{aligned}
M V_{0}^{c} & =\sum_{t=1}^{\infty} \frac{E_{0}\left[d_{t}^{e}\right]}{(1+r)^{t}}+\left\{\sum_{t=T+1}^{\infty} \frac{E_{0}\left[d_{t}^{m}\right]}{(1+r)^{t}}-\frac{E_{0}[X]}{(1+r)^{T}}\right\} \\
& =M V_{0}^{e}+O P V_{0}
\end{aligned}
$$


The valuation expression equation (9) can be used to obtain an indirect estimate of $M V_{0}^{e}$, by valuing both $M V_{0}^{c}$ and $O P V_{0}$ and taking the difference, but this two-stage procedure is rarely used in practice. Another approach would be to compute value on a diluted per share basis. However, the applicable dilution correction to be used in per share calculations is equivalent to assuming that the proportion of new shares to be issued under the ESO relative to existing shares is equal to $O P V_{0} / M V_{0}^{e}{ }^{17}$ The direct method of valuing existing shares in Eq. (7) requires subsequent share issues to third parties, in this case $m$, to be measured at fair value. The indirect method of Eq. (8) does not distinguish between the value of equity in issue and possible new shareholders in the future. Any such share issues are therefore measured at the resources flowing to the enterprise at time of issue, i.e., the exercise price, $X$. Eqs. (7), (8) reveal the importance of clarity in the treatment of future dilution in the valuation of current equity claims. We show below that the issue of identifying the appropriate net dividend stream has implications for the choice of ESO accounting method.

Our analysis assumes that no new ESO contracts will be issued in the future. However, future ESO grants could be accommodated in our analysis. To see this, assume the firm is expected to issue additional ESOs at dates $T_{i} \geq$ $T(i=1,2, \ldots)$, the projected value at grant date of which we denote as $E_{0}\left[O P V_{T i}^{\text {future }}\right]$. Dividends payable to non-current shareholders, $d_{t}^{m}$, will be shared between the holders of the current and future ESOs. Suppose the valuation is carried out as in Eq. (8), based on the forecast net cash flows to and from all equity claimants., It can be shown by induction that the value of that dividend stream will equal the present value of all claims, including prospective ESO grants, i.e.,

$$
M V_{0}^{c}=M V_{0}^{e}+O P V_{0}+\sum_{t \subseteq T_{i}}^{\infty} \frac{E_{0}\left[O P V_{t}^{\mathrm{future}}\right]}{(1+r)^{t}} .
$$

We ignore this aspect of valuation because no proposed ESO accounting method involves recognition of future ESOs. We treat future option grants as an un-modeled source of "other information" in the empirical analysis, omitting the $\sum_{t \subset T_{i}}^{\infty} E_{0}\left[O P V_{t}^{\text {future }}\right] /(1+r)^{t}$ term in (10), since all our estimating equations based on the different accounting treatments for ESOs are similarly affected by this omitted variable. In the remainder of our theoretical modeling, we therefore continue to assume that no further ESO contracts will be written.

\footnotetext{
${ }^{17}$ We can see from Eq. (9) that the dilution correction needed to get the correct market value per share requires $\frac{M V_{0}^{e}}{n^{e}}=\frac{M V_{0}^{e}+O P V_{0}}{n^{e}+n^{m}}$. This requirement implies that $\frac{n^{m}}{n^{e}}=\frac{O P V_{0}}{M V_{0}^{e}}$. Current accounting rules for computing EPS makes an adjustment based on option intrinsic values instead of their fair values. As a result, fully diluted EPS will be biased upwards. Core et al. (2002) make a similar observation.
} 


\subsection{Residual income valuation}

The next step is to examine what happens when accounting numbers in the place of dividends are used to value equity. The residual income valuation (RIV) model is a natural vehicle for this purpose because it expresses economic value in terms of a book value anchor and a premium based on the discounted present value of the excess of future earnings over the normal return on book value (Edwards \& Bell, 1961; Peasnell, 1982; Preinreich, 1938; Ohlson, 1995). This provides a method of capturing all the wealth effects of ESOs, both in how they are captured in equity book value and how they affect the measurement of earnings. ${ }^{18}$ If the clean surplus accounting relation holds then the dividend discount model can be expressed in terms of current equity book value and future residual incomes, as follows:

$$
M V_{0}^{i}=B V_{0}^{i}+\sum_{t=1}^{\infty} \frac{E_{0}\left[R I_{t}^{i}\right]}{(1+r)^{t}}
$$

where $B V_{0}^{i}$ and $R I_{t}^{i}$ are the book value of equity at time 0 and the residual income for period $t$, respectively, using ESO accounting method $i$. Residual income is a random variable, defined as $R I_{t}^{i}=N I_{t}^{i}-r B V_{t-1}^{i}$. $N I_{t}^{i}$ is net income for period $t$ using accounting method $i$. If accounting violates the clean surplus relation, future residual income flows would have to be adjusted by expected dirty surplus flows in order to ensure articulation between Eq. (11) and the relevant dividend discount model.

The four alternative accounting methods described in Section 1.2 establish different measures for (components of) equity book value and accrued ESOrelated expenses. We now consider the implications of applying the RIV model to items measured under the accounting alternatives. Specifically, given that the alternative accounting treatments adopt different perspectives on the inclusion of ESO-related accounting items, we consider the relation between value estimates based on the RIV model and the value of the underlying claims of owners and managers. This analysis has implications for the specification of the empirical tests that follow in Section 2.

\footnotetext{
18 A natural alternative approach would be to use the abnormal earnings growth (AEG) model developed by Ohlson and Juettner-Nauroth (2005) as it does not assume that clean surplus accounting is employed and can easily handle changes in the numbers of shares in issue. It can readily be shown that when net income is measured under any of the four ESO accounting approaches considered in this paper the AEG model will produce a value estimate equal to $M V_{0}^{e}$ $+O P V_{0}$, if dividends are defined on a total net dividends basis. Furthermore, if dividends are defined on a per share basis then the AEG value will always equal $M V_{0}^{e}$, regardless of the basis on which the accounting is done. As we shall see, this is not always the case with the RIV model. While this makes the AEG model a potentially extremely useful model for many practical investment purposes, it means it is not a suitable engine for obtaining insights into how equity market value reflects ESO transactions. For the present study, an advantage of the RIV model is that it makes use of both balance sheet and income statement items, whereas the balance sheet is superfluous in the AEG model.
} 
Differences in RIV estimates may arise because of differences in the magnitude of recognized equity book value, or differences in the timing or magnitude of income, or both. Option expense is not charged in arriving at net income under Method 1. Option expense under accounting Methods 2, 3 and 4 is based on the fair value of the ESO at grant date $\left(O P V_{0}\right)$ apportioned over the $T$-year vesting period. We assume without loss of generality that option expense is computed on a straight-line basis, with $O P V_{0} / T$ being allocated to each period.

Equity book value differences arise depending on whether the accounting method recognizes an ESO-related pre-paid compensation asset and because of differences in the classification of the associated option as an equity account or a liability. No asset or option credit is recognized at date 0 under Method 2 (SFAS 123 (revised)), in contrast to Methods 3 and 4 (Exposure Draft and Asset and Liability). The amount initially recognized as a pre-paid compensation asset under Methods 3 and 4 equals $O P V_{0}$. The corresponding credit is treated as equity under Method 3 and as a liability under Method 4.

There are several implications for the residual income model of the different ways of accounting for ESOs. In Methods 3 and 4, the impact of the recognition of an asset that is subsequently amortized is straightforward. The recognition of the pre-paid compensation asset simply changes the balance between current book value and future residual income. Under Method 4, the credit arising from recognition of the asset at grant date is treated as a liability, implying that equity book value at that date is identical to Method 1 ( $A P B$ 25 ), where no asset or liability is recognized. The difference between the two methods appears in the streams of future residual incomes and (we shall see later) in the resulting present values. Methods 2 and 3, on the other hand, treat the option account as a form of paid-in capital. The only difference between the two methods is that the "equity" builds up slowly under Method 2 (with nothing being recognized at grant date), whereas it is all recognized at grant date under Method 3. Therefore, equity book value under Method 3 differs at grant date from the equity book value amounts reported under Methods 1,2 and 4.

We now examine the consequences of applying the RIV model (11) to equity book value and projected residual income flows obtained under the four accounting alternatives. Our main objective in this section is to show how estimated value obtained from the residual income model relates to the value of current equity outstanding.

\subsubsection{Method 1}

Method 1 is the benchmark model. The other three accounting alternatives can be related to the relevant accounting numbers obtained under Method 1 . We assume that the net income flows are linked to the underlying dividend flows and equity book values by assuming that the clean surplus relation holds in this base accounting system, i.e., changes in equity book value equal net income less dividends paid. However, note that for valuation purposes 
dividend policy irrelevance is assumed to hold. Any exogenous change in the timing of dividend payments will not affect the value of the firm because the firm and equity claimants are assumed to be able to borrow and lend at the same cost of capital.

The value of the firm obtained by applying expression (11) to the residual income flows under Method 1 is as follows:

$$
M V_{0}^{1}=B V_{0}^{1}+\sum_{t=1}^{\infty} \frac{E_{0}\left[R I_{t}^{1}\right]}{(1+r)^{t}}
$$

where

$$
R I_{t}^{1}=N I_{t}^{1}-r B V_{t-1}^{1}
$$

and

$$
N I_{t}^{1}=\left\{\begin{array}{cc}
\left(d_{t}-X\right)+\left(B V_{t}^{1}-B V_{t-1}^{1}\right) & \text { for } t=T, \\
d_{t}+\left(B V_{t}^{1}-B V_{t-1}^{1}\right) & \text { for } t \neq T
\end{array}\right.
$$

for an ESO that is exercised at time $T$ and $N I_{t}^{1}=d_{t}+\left(B V_{t}^{1}-B V_{t-1}^{1}\right)$ at all times for ESOs that are not exercised. Substituting the net income and equity book value values for Method 1 into Eq. (12) and canceling and collecting terms gives:

$$
M V_{0}^{1}=\sum_{t=1}^{\infty} \frac{E_{0}\left[d_{t}\right]}{(1+r)^{t}}-\frac{E_{0}[X]}{(1+r)^{T}}
$$

Valuation expression (13) is identical to the value obtained using the mixed surplus dividend discount model in Eq. (8). We therefore know from Eq. (9) that $M V_{0}^{1}=M V_{0}^{c}=M V_{0}^{e}+O P V_{0}$. Since $O P V_{0}$ must be positive prior to expiration date, applying the RIV model to accounting numbers prepared under Method 1 over-estimates the value of current equity. The reason is that Method 1 ignores stock options in recognized net income and equity book value.

\subsubsection{Method 2}

In the first $T$ periods, net income under Method 2 differs from net income under Method 1 by an amount equal to the recognized option expense. However, as can be seen in Table 1, the credit associated with the option expense is included in paid-in capital. The two entries therefore cancel and the equity book value under Method 2 is always the same as equity book value under Method 1, i.e., $B V_{t}^{2}=B V_{t}^{1}(t=0,1, \ldots)$. This implies that the capital charge levied to arrive at residual income is the same under the two methods. It therefore follows that Method 2 residual incomes will be less than their Method 1 counterparts by an amount equal to the option expense: 
$R I_{t}^{2}=R I_{t}^{1}-O P V_{0} / T$. As a result, use of ESO Method 2 accounting numbers in (11) yields

$$
\begin{aligned}
M V_{0}^{2} & =M V_{0}^{1}-\sum_{t=1}^{T} \frac{O P V_{0}}{T(1+r)^{t}} \\
& =M V_{0}^{e}+\left[1-\frac{1-(1+r)^{-T}}{r T}\right] O P V_{0} .
\end{aligned}
$$

ESO accounting Method 2 recognizes option equity over time, as a by-product of recognizing option expense. Generally, the resulting valuation provides an estimate of neither the $M V_{0}^{e}$ nor $M V_{0}^{e}+O P V_{0}$. Only in the special case where $r=0$ will $M V_{0}^{2}=M V_{0}^{e}$. More generally, for $r>0$ and $M V_{0}^{2}>M V_{0}^{e}, M V_{0}^{2}$ is an increasing function of both $r\left(\partial M V_{0}^{2} / \partial r>0\right)$ and $T\left(\partial M V_{0}^{2} / \partial T>0\right)$ and falls within the range, $M V_{0}^{e} \leq M V_{0}^{2}<M V_{0}^{e}+O P V_{0}{ }^{19}$ The boundary to which $M V_{0}^{2}$ is closest will vary from case to case. However, for option grants where $T=5$ (a typical option grant vesting period), $M V_{0}^{2}$ will be closer to $M V_{0}^{e}$ than to $M V_{0}^{e}+O P V_{0}$ as long as $r$ is less than $28.6 \%$, for with these values $M V_{0}^{2} \cong M V_{0}^{e}+\frac{1}{2} O P V_{0}$.

This result is troubling, given that Method 2 is the approach that both the FASB and the IASB have chosen to require companies to follow in the future. The reason why this result occurs can be gleaned from Table 1 . Method 2 can be viewed as a variant of model 3, where an ESO asset is recognized at grant date and then immediately written off to equity, after which the asset is amortized as ESO expense against income. The effect of this is that dirty surplus accounting is taking place. Method 2 is the only one that involves dirty surplus accounting. Moreover, because the asset has disappeared, no interest charge is made in arriving at residual income. One way the financial statement user could "fix" this problem would be to include such a charge in arriving at residual income; however, that would require the user to estimate and track the off-balance sheet asset-in effect, to compute all the numbers needed to implement Method 3.

\subsubsection{Method 3}

Net income under Method 3, is the same as under Method 2. On the other hand, the immediate recognition of an asset gives rise to a credit that is treated as equity under Method 3 , thus giving rise to a difference in equity book value at date 0 under the two methods, i.e., $B V_{0}^{3}=B V_{0}^{1}+O P V_{0}=B V_{0}^{2}+O P V_{0}$. This

\footnotetext{
19 This result is not simply an artifact of our assumption that amortization is charged on a straightline basis. Any allocation scheme that assigns the proportion $\delta_{t}$ of $O P V_{0}$ as ESO expense in period $t$ and satisfies the conditions that all $0 \leq \delta_{t} \leq 1$ such that $\sum_{t=1}^{T} \delta_{t}=1$ will result in a value for $M V_{0}^{2}$ that falls somewhere between $M V_{0}^{e}$ and $M V E_{0}^{e}+O P V_{0}$. This follows from the fact that any discounted sum of ESO expense charges must result in $\sum_{t=1}^{T} \frac{\delta_{t}}{(1+r)^{t}}<1$ if $r>0$.
} 
difference in book values diminishes with time, as the ESO asset is amortized, such that $\left.B V_{t}^{3}=B V_{t}^{1}+O P V_{0}(T-t) / T\right)$. At time $T$, the asset is fully amortized and $B V_{T}^{3}=B V_{T}^{1}$. The residual income stream reflects both the amortization charges and the extra (but diminishing) equity book value. Applying valuation expression (11) to the equity book value and residual income flows and substituting from (14), we obtain

$$
\begin{aligned}
M V_{0}^{3} & =\left\{M V_{0}^{e}+\left[1-\frac{1-(1+r)^{-T}}{r T}\right] O P V_{0}\right\}+O P V_{0}-\left[1-\frac{1-(1+r)^{-T}}{r T}\right] O P V_{0} \\
& =M V_{0}^{1}
\end{aligned}
$$

because $M V_{0}^{3}=M V_{0}^{e}+O P V_{0}$. Method 3 results in an over-estimate of the value of existing equity but correctly values the total of the claims of $e$ and $m$. As with Method 1, Method 3 is a form of mixed surplus accounting because it reflects dividends flowing to existing and potential future equity holders.

\subsubsection{Method 4}

Under Method 4, an asset is recognized immediately and the associated credit is treated as a liability. As a consequence, date 0 equity book value is the same as under Method 1 because the asset and liability fully offset each other. The asset is amortized in the same way as under Method 3, but net income also includes gains and losses on marking-to-market the liability:

$$
\begin{aligned}
N I_{t}^{4} & =d_{t}+\left(B V_{t}^{4}-B V_{t-1}^{4}\right) \\
& =N I_{t}^{1}-\frac{O P V_{0}}{T}-\Delta O P V_{t}
\end{aligned}
$$

where $\triangle O P V_{t}=O P V_{t}-O P V_{t-1}$ represents the change in the market value of the liability. The equity book values of Methods 1 and 4 diverge during the vesting period by an amount equal to the accumulated charges against net income:

$$
B V_{t}^{4}=B V_{t}^{1}-O P V_{0}\left(\frac{t}{T}\right)-\sum_{s=1}^{t} \Delta O P V_{s}, \quad t=1,2, \ldots, T-1
$$

As shown in Table 1, at date $T$ the marked-to-market book value of the ESO liability plus the exercise proceeds will equal the market value of the shares issued to $m$ :

$$
\begin{aligned}
M V_{T}^{m}-X & =O P V_{T} \\
& =O P V_{0}+\sum_{t=1}^{T} \Delta O P V_{t} .
\end{aligned}
$$

It can be seen from Eqs. (17) (18) that equity book values under Methods 1 and 4 are equal at vesting date $T$ and thereafter 


$$
\begin{aligned}
B V_{T+s}^{4} & =B V_{T+s}^{1}-O P V_{0}-\sum_{t=1}^{T} \Delta O P V_{t}+M V_{T}^{m}-X \quad s=0,1 \\
& =B V_{T+s}^{1} .
\end{aligned}
$$

The residual income valuation rule can be applied, using Eqs. (16) (17) (19), as follows:

$$
\begin{aligned}
M V_{0}^{4}= & B V_{0}^{4}+\sum_{t=1}^{\infty} \frac{E_{0}\left[R I_{t}^{4}\right]}{(1+r)^{t}} \\
= & B V_{0}^{1}+\sum_{t=1}^{T} \frac{E_{0}\left[R I_{t}^{1}\right]-\frac{O P V_{0}}{T}-\Delta O P V_{t}-r\left[-O P V_{0}\left(\frac{t-1}{T}\right)-\left(O P V_{t-1}-O P V_{0}\right)\right]}{(1+r)^{t}} \\
& +\sum_{t=T+1}^{\infty} \frac{E_{0}\left[R I_{t}^{1}\right]}{(1+r)^{t}} .
\end{aligned}
$$

Collecting terms in Eq. (20), we know from our results for Method 1 that

$$
\begin{aligned}
M V_{0}^{4} & =B V_{0}^{1}+\sum_{t=1}^{\infty} \frac{E_{0}\left[R I_{t}^{1}\right]}{(1+r)^{t}}-O P V_{0} \\
& =\sum_{t=1}^{\infty} \frac{E_{0}\left[d_{t}\right]}{(1+r)^{t}}-\frac{E_{0}[X]}{(1+r)^{T}}-O P V_{0}
\end{aligned}
$$

Insight into this result can be obtained by recalling that all the ESO expenses and gains and losses on the ESO liability are accounted for on a "super-clean surplus" basis. In which case, it follows that Method 4 will yield an estimate of value that is a function of $d_{t}$ and $M V_{T}^{m}$. Eq. (21) implies that $M V_{0}^{4}=M V_{0}^{e}$.

Method 4 is the only one of the four accounting methods considered that provides an unbiased estimate of the value of existing equity. Equity is recognized if (and only if) new shares are issued, and these are then accounted for at market value. Such super-clean accounting guarantees that residual income is on a "proprietary" basis relevant to the valuation of shares in issue.

\section{Empirical design}

\subsection{Rationale}

The analysis in the prior section reveals that certain approaches to accounting for ESOs could lead to systematically biased RIV estimates of current 
shareholders' wealth, where those estimates are based on forecasted residual income under the relevant accounting method. The next step we take is to pass to the opposite extreme and consider the accuracy of valuation estimates that are based only on the most recent balance sheet and earnings numbers. One rationale for doing this is that it allows the possibility that theoretically inferior accounting methods might nevertheless yield superior value estimates in a limited information setting. The empirical valuation relations can provide insights into whether single-period accounting numbers provide parsimonious representations of the larger information sets that investors actually use to set prices. ${ }^{20}$ To retain a link with our theoretical analysis, we base our analysis on current equity book value and current residual income, or components thereof. Our approach is closely related to that of Bell et al. (2002), who compare the value relevance of accounting amounts based on what we call here the APB 25 and SFAS 123 (revised) methods of accounting for ESOs for a sample of computer software firms.

One caveat should be borne in mind when considering our empirical results. The information necessary to implement the two approaches with least theoretical support-the APB 25 and SFAS 123 (revised) methods-are easiest to compute from publicly available data, whereas, the Asset and Liability method-the approach best-supported by theory-requires marking-to-market estimates of option values. To the extent that the additional information required by Method 4 is estimated with error, empirical tests will be biased against the superiority of this method. We explain our procedures in the next section.

\subsection{Estimating equations}

The key empirical issue for our study is whether different approaches to accounting for ESOs result in the recognition of ESO-related amounts that have different dynamic properties, and hence different valuation characteristics that we can measure. One study that explicitly addresses the question of whether allowing different earnings components to have different dynamics and therefore different valuation parameters is Barth, Beaver, Hand, and Landsman (2005). That study's main finding is that out-of-sample predictions of equity value improve with sequential levels of earnings disaggregation, moving from total earnings to cash flow, and from total accruals to cash flow plus four major accrual components. A second relevant finding in Barth et al. (2005) is that imposing a linear information structure as in Ohlson (1995) when estimating valuation model parameters makes very little difference, either in terms of valuation coefficient estimates or in terms of

\footnotetext{
${ }^{20}$ A parallel can be drawn here with the use of simple multiples of accounting numbers that loom large in professional publications and that research has shown can often out-perform valuation methods that have more theoretical support (e.g., Liu, Nissim, \& Thomas, 1999). This still leaves open the possibility, of course, that the rankings might be different again if the measures were combined with other sources of information available to investors.
} 
the out-of-sample equity value prediction errors. Taken together, the findings from Barth et al. (2005) suggest that we develop a research design that exploits valuation differences in ESO equity book value and earnings amounts across the four methods. They also suggest that when making these comparisons it is necessary neither to measure nor to impose the implied linear information dynamics of the ESO components applicable to each accounting method.

We expect out-of-sample predictions of contemporaneous equity to improve as more balance sheet and income statement items attributable to ESOs are separately included in the estimating equations. ${ }^{21}$ This leads us to expect that prediction errors will decline monotonically as one moves from Method 1 to Method 4. However, based on the theoretical analysis in Section 1.4, we expect the lowest prediction errors for Method 4, the highest prediction errors for Methods 1 and 3, and prediction errors between the two extremes for Method 2. These theoretical expectations are dependent on current residual income and book value being sufficient for projecting future residual income. Whether this is the case is an empirical matter. We next describe a "comprehensive" estimating equation that includes accounting amounts from the four accounting methods, and which transforms a comparison of accounting methods into an additional disclosure issue.

Methods 1 and 2 can be thought of as being nested within Method 3, which in turn can be thought of as being nested within Method 4. To see this, note that for a given firm $i$, under Method $1, R I_{t}^{1}=N I_{t}^{1}-r B V_{t-1}^{1}$. For Method 2, equity book values are the same as with Method 1 and incomes (and therefore residual incomes) differ only by the amount of option expense, i.e., $B V_{t}^{2}=B V_{t}^{1}$ and $R I_{t}^{2}=R I_{t}^{1}-O P T I O N E X P E N S E_{t}$, where OPTIONEX$P E N S E_{t}$ is the empirical counterpart of $O P V_{0} / T$. For Method 3, net income is the same as with Method 2 but equity book value differs by the amount of net unamortized option equity (OPTIONEQUITY), NETESO ${ }_{t} \equiv$ $O P T I O N E Q U I T Y_{t}-\sum_{s=1}^{t} O P T I O N E X P E N S E_{s}$, resulting in different capital charges: $B V_{t}^{3}=B V_{t}^{1}+N E T E S O_{t}$, and $R I_{t}^{3}=R I_{t}^{1}-O_{\text {OPTIONEXPENSE }}-$ $r \times N E T E S O_{t-1}$.

Lastly, turning to Method 4, $B V_{t}^{4}$ equals $B V_{t}^{1}$ less the cumulative option expense and accumulated fair value gains and losses associated with the marking-to-market of the option liability $(O P T I O N L I A B)$, plus the additional equity attributable to the fair value of the option liabilities at exercise that is transferred to equity (see Table 1). The last component of $B V_{t}^{4}$, the fair value at exercise of the option liabilities, creates a potential problem because

\footnotetext{
${ }^{21}$ This might not happen if the items in question were included as part of book value of equity or residual income, because then the ESO items would be constrained to have the same valuation coefficients as other components of book value and residual income. Based on the findings in Barth et al. (2005), disaggregation of balance sheet and income statement components should improve out-of-sample predictions. However, our comparisons are not between aggregated and disaggregated accounting numbers but rather between equations that include or exclude ESO items that could have predictive power in their own right.
} 
such information is not publicly available. However, this problem can be circumvented by noting that $B V^{4}=B V^{3}-O P T I O N L I A B$, because prior to exercise, OPTIONLIAB and OPTIONEQUITY differ by the amount of the sum of the changes in OPTIONLIAB included in income under Method 4; when ESOs are exercised or expire, OPTIONLIAB is closed into book equity. Thus, we can measure equity book value under Method 4 without having to calculate all of its components, particularly the number of options exercised or expired.

Method 4's net income equals net income under Method 3 plus the periodic marking-to-market gains and losses on the option liability. Thus Method 4's residual income contains an additional capital charge component, $r \times$ $O P T I O N L I A B$, reflecting the market value of the option liability. Hence, $R I_{t}^{4}=R I_{t}^{1}-O P T I O N E X P E N S E_{t}-D_{O P T I O N L I A B_{t}}-r \times N E T E S O_{t-1}+r \times$ $O P T I O N L I A B_{t-1}$, where DOPTIONLIAB $B_{t}$ is the change in the market value of the option liability from $t-1$ to $t$.

Based on the above expressions for equity book value and residual income under the four ESO accounting methods, we generate out-of-sample equity value predictions by estimating versions of the estimating equations based on Method 4, but expanding out the components of residual income and equity book value as above:

$$
\begin{aligned}
& M V E_{i t}=\alpha_{0}+\left\{\alpha_{1} R I_{i t}^{1}+\alpha_{2} \text { OPTIONEXPENSE } E_{i t}+\alpha_{3} \text { OPTIONLIA } B_{i t}\right. \\
& \left.+\alpha_{4}\left[r \times \operatorname{NETSESO}_{i, t-1}\right]+\alpha_{5}\left[r \times \text { OPTIONLIAB } B_{i, t-1}\right]\right\} \\
& +\left\{\alpha_{6} B V_{i t}^{1}+\alpha_{7} \text { NETESO }_{i t}+\alpha_{8} \text { OPTIONLIAB }_{i t}\right\}+\varepsilon_{i t} .
\end{aligned}
$$

The terms in the first set of $\{\cdot\}$ brackets on the right hand side of Eq. (22) contains the components of residual income for Method 4, and the terms in the second set of \{\} brackets contains the components of equity book value for Method 4. The other methods can be obtained by constraining relevant coefficients in (22) equal to zero. The information set in Eq. (22) is equivalent to Method 3 if $\alpha_{3}=\alpha_{5}=\alpha_{8}=0$. Method 2 is nested in Method 3 is equivalent to adding the further restriction $\alpha_{4}=\alpha_{7}=0$. Finally, Method 1 is equivalent to adding the further restriction $\alpha_{2}=0$ (i.e. the only parameters estimated in Eq. (22) are $\alpha_{1}$ and $\alpha_{6}$ ). The resulting estimating equations relating to the Methods 1 through 3 are therefore as follows

$$
\begin{gathered}
M V E_{i t}=\alpha_{0}+\alpha_{1} R I_{i t}^{1}+\alpha_{6} B V_{i t}^{1}+\varepsilon_{i t} \\
M V E_{i t}=\alpha_{0}+\alpha_{1} R I_{i t}^{1}+\alpha_{2} \text { OPTIONEXPENSE }_{i t}+\alpha_{6} B V_{i t}^{1}+\varepsilon_{i t} \\
M V E_{i t}=\alpha_{0}+\left\{\alpha_{1} R I_{i t}^{1}+\alpha_{2} \text { OPTIONEXPENSE }_{i t}+\alpha_{4}\left[r \times N E T E S O_{i, t-1}\right]\right\} \\
+\left\{\alpha_{6} B V_{i t}^{1}+\alpha_{7} \text { NETESO }_{i t}\right\}+\varepsilon_{i t} .
\end{gathered}
$$


We estimate all four equations using unscaled data (Barth \& Kallapur, 1996) and using year fixed-effects. ${ }^{22}$

As noted above, our primary concern is the relative predictive-ability of out-of-sample equity market value using the four different methods of accounting for ESOs. Therefore, we make no predictions regarding the magnitudes of equity book value and residual income coefficients across the various specifications. However, in our discussion of the results, we assess their reasonableness, including their signs, and compare their magnitudes with those from extant research. We note that the Ohlson linear information model suggests that "other information" will generally be relevant in explaining equity values when prices lead earnings. ${ }^{23}$ The intercept estimates (and year fixed effects) in Eqs. (22) (23a-c) will capture the average effect of other information. This will include the mean valuation effects of accounting components that are omitted from a specific accounting method. Thus the regression intercepts effectively capture the differential valuation bias effects as one moves from one ESO accounting method to another.

\subsection{Jack-knifing and error metrics}

We use a jack-knifing procedure to generate contemporaneous out-of-sample equity market value predictions. The principal reason for using jack-knifing is that we seek to obtain equity value predictions for each firm without using that firm's data to generate its predicted equity value. The prediction of firm $i$ 's equity value in year $t$ is the predicted value from the valuation equation using estimated coefficients from the valuation equation and all data except firm $i$ 's in year $t$. Because firm $i$ 's data in year $t$ are not used to estimate the coefficients, each prediction is out-of-sample. Following Barth et al. (2005), we set negative predicted equity market values to zero because equity market values cannot be negative. A key feature of the jack-knife procedure is that we obtain statistics for hypothesis testing that do not rely on unknown parametric distributions, e.g., normality (Noreen, 1989). ${ }^{24}$

\footnotetext{
${ }^{22}$ Although Barth and Kallapur (1996) provides convincing reasons to estimate cross-sectional equity valuation models similar to ours using unscaled data, there are several additional reasons to avoid estimating our equations on a per share basis. First, our theoretical analysis suggests that equations using different accounting methods for ESOs require different share amounts as scalars. This would amount to throwing away the baby with the bath water in that we could no longer carry out any meaningful tests of the valuation effects of different methods of accounting for ESOs. Second, per share deflation for all but Method 4 would require estimating additional shares relating to ESOs based on option fair value. This would needlessly introduce the potential of additional measurement error in the affected models. Nonetheless, we also estimate our equations using two deflators, sales and total assets, to address the possibility that our findings are sensitive to scale bias arising from estimation using unscaled data.

${ }^{23}$ Following prior research (e.g., Barth, Beaver, Hand, \& Landsman, 1999), the different versions of Eqs. (22) and (23) that we estimate include intercepts and error terms to allow for the average valuation effects of unmodeled other information. We acknowledge that omission of unmodeled other information variables could bias the coefficients of the included variables.

${ }^{24}$ The jack-knife procedure assumes that parameter estimates are generated from a randomly collected sample and that observations in the sample are independent.
} 
For each valuation equation corresponding to Methods 1 through 4, we construct a distribution of prediction errors. For each distribution, we calculate two commonly employed prediction error metrics, absolute percentage error, $\mathrm{AE}$, and squared percentage error, $\mathrm{SE}$ :

$$
\begin{aligned}
\mathrm{AE} & =\operatorname{abs}\left(M V E_{i t}-\text { predicted } M V E_{i t}\right) / M V E_{i t} \quad \text { and } \\
\mathrm{SE} & =\left(\left(M V E_{i t}-\text { predicted } M V E_{i t}\right) / M V E_{i t}\right)^{2} .
\end{aligned}
$$

We test the statistical significance of differences between mean (median) values of absolute and squared prediction errors between accounting methods using a paired $t$-test (Hogg \& Tanis, 2001, p. 442) and the non-parametric Wilcoxon signed-rank test, that is not sensitive to outliers.

We also use the prediction errors associated with each of the four accounting methods based on their relative ranks using two approaches. The first approach simply determines the frequency with which a particular accounting method has the lowest prediction errors among the four methods. This is, in essence a pure "horse race" approach which asks the question "which model "wins' most often?" 25 The implicit cost function with the pure horse race approach is that "order of finish" other than first is irrelevant. The second approach determines the average rank-or, continuing the horse race analogy, the average order of finish. The average rank approach adopts a different implicit cost function that penalizes a method for having a low relative rank even if it has the most frequent number of lowest forecast errors.

\subsection{Empirical variable definitions and measurement issues}

This section describes how we measure the variables used to estimate Eqs. (22) (23). $N I$ equals net income before extraordinary items and discontinued operations; ${ }^{26} B V E$ and $M V E$ are the end-of-fiscal year book and market values of common equity; OPTIONLIAB is an estimate of end-of-fiscal year ESO option fair value (described below). OPTIONEXPENSE is defined on an after-tax basis, measured as reported net income minus after-tax $S F A S 123$ pro forma net income, which is taken from the SFAS 123 disclosures. OPTIONEQUITY is the sum of current and past amounts credited to equity resulting from ESO grants. OPTIONEQUITY is fixed at date of grant and is, therefore, measured at historical cost. In contrast, OPTIONLIAB is markedto-market every year. We measure the cost of equity, $r$, in two ways. First, following Dechow et al. (1999), Barth et al. (1999, 2005), and Bell et al.

\footnotetext{
${ }^{25}$ We thank Jim Ohlson for suggesting we compare the four accounting methods using this approach.

${ }^{26}$ Bell et al. (2002) point out that although defining residual income based on net income before extraordinary items and discontinued operations violates the clean surplus assumption in Ohlson (1995), it eliminates potentially confounding effects of large one-time items and is consistent with prior empirical research (e.g., Barth et al., 1999, 2005; Dechow, Hutton, \& Sloan, 1999; Hand \& Landsman, 2005). Ohlson (1999, p. 160) concludes that this approach is justified in empirical work because one-time items are likely to have limited forecasting ability.
} 
(2002), we set $r$ equal to 12 percent, the long-term return on US equities. Second, we estimate the firm-specific cost of equity using CAPM betas obtained from ValueLine. ${ }^{27}$ For the sake of brevity, we focus the discussion on results assuming the constant cost of equity. However, we highlight any important differences in findings based on firm-specific cost of capital estimates, where appropriate.

Unlike OPTIONEXPENSE, which can be deduced as the difference between reported net income and $S F A S 123$ pro forma net income, the other option value-based variables, OPTIONLIAB and OPTIONEQUITY, must be estimated. OPTIONEQUITY ${ }_{t}$ is the sum of grant date ESO fair values, computed as the accumulation since 1995 of the number of ESOs granted each year multiplied by the weighted-average fair value per share at grant date. A complication is that SFAS 123 pro forma ESO expenses and related disclosures are based on ESOs granted from 1995 onwards but the disclosures do not provide separate totals for the number of options outstanding arising from grants before and after 1995. Because we estimate the option fair value $(O P T I O N L I A B)$ using the total number of options granted and outstanding as of a particular balance sheet date, there is an inconsistency between measurement of the income statement variable, OPTIONEXPENSE, and the measurement of equity book value under Method $4 .^{28}$

We use the Black-Scholes (1973) option pricing model to estimate fair value of ESOs outstanding at each balance sheet date so that we can construct OPTIONLIAB using disclosed parameter amounts taken from the SFAS 123 disclosures. ${ }^{29}$ The related parameters we use are

1. Exercise price of the option: the current year's weighted exercise price for all outstanding ESOs.

2. Expected stock-return volatility: reported expected stock-return volatility for options issued in the current year, taken from the SFAS 123 disclosures.

3. Risk-free interest rate: reported risk-free interest rate for options issued in the current year, taken from the SFAS 123 disclosures.

\footnotetext{
${ }^{27}$ In particular, we set the $r$ equal to $r_{f}+\beta \times 0.06$, where $r_{f}$ is the prevailing 3-month t-bill rate at the beginning of each fiscal year and 0.06 is an estimate of the market risk premium, $r_{m}-r_{f}$. Our estimate of the market risk premium is similar to the estimate of the long-run equity risk premium in Ibbotson Associates (2005) over our sample period.

28 There are two additional inconsistencies in the measurement of equity book value and residual income for all but Methods 1 and 2. The first arises from the fact that OPTIONEXPENSE is on an after-tax basis, and we ignore income tax effects in our measurement of equity book value under Methods 3 and 4 . In principle, equity book value under these two methods should reflect the same accumulated before-tax OPTIONEXPENSE charge. The second is that OPTIONEXPENSE reflects adjustments for anticipated forfeitures, but book equity under Methods 3 and 4 cannot be adjusted appropriately because we do not have details of the forfeitures.

${ }^{29} \mathrm{Li}$ and Wong (2005) point out that Black-Scholes estimates of ESO fair values result in the overstatement of ESO expense compared to the amount that would be obtained using a warrant pricing model. To the extent that our use of Black-Scholes fair value estimates creates measurement error in option expense, option equity, and option liabilities, this will reduce our ability to distinguish between the models' relative forecasting ability.
} 
4. Expected dividend yield: reported expected dividend yield for options issued in the current year, taken from SFAS 123 disclosures.

5. Time to maturity: reported expected life for options issued in the current year, adjusted for the time lapses since issuance by using half of expected life of newly granted options.

Because the SFAS 123 disclosures do not provide detail on these input variables for different tranches of options, we assume the option grants are issued evenly across years, and no options are exercised before the end of their expected lives. Thus, the average life for all options outstanding is equal to half of expected life of newly granted options. In addition, for firm years with missing input data, we substitute the average values from the available years.

The final key parameter used as an input to the Black-Scholes option pricing model is the price of the underlying stock. Option pricing theory would suggest that we use the stock price at fiscal year end. However, Aboody (1996) notes that because ESO value increases with the price of underlying stock, regressing stock prices on ESO values creates an endogeneity problem because stock price would appear in both the dependent and independent variables. Failure to take account of this endogeneity would result in estimated ESO values that are positively correlated with regression error terms, and the resulting coefficients on the option fair value-based variables would be biased. To address the endogeneity problem, we estimate OPTIONLIAB using the predicted stock price from a per share version of Eq. (23a). By construction, the estimated ESO fair values obtained from this first-stage procedure are not correlated with the error terms in the second-stage valuation Eqs. (22) (23b) (23c). When predicted stock prices from the first-stage regression are negative, we set them to zero.

\section{Sample and data}

The sample comprises $1,354(1,204)$ firm-year observations drawn from the S\&P Industrial Index, i.e. the S\&P-500, where the former (latter) sample is based on residual income computed using the constant $12 \%$ (ValueLine firmspecific) equity cost of capital. The sample period includes fiscal years 19972001. The first year for which SFAS 123 data are available is 1996 . The sample period starts in 1997 because construction of the change in option liability variable requires one-period lagged data. The potential sample for use in cross-sectional regressions is 2,500 observations ( 5 years $\times 500$ firms). We require firms to have earnings, equity market value, (non-negative) equity book value, and ESO data necessary to estimate equity book value and residual income under all four ESO accounting methods. ${ }^{30}$ To mitigate the

\footnotetext{
${ }^{30}$ Following Bell et al. (2002), we require positive beginning owner's equity to ensure that the firm's cost of capital in calculating abnormal earnings $\left(r B V E_{t-1}\right)$ is positive. Also for the case of the firm-specific equity cost of capital sample, we also require non-missing data for beta.
} 
effects of outliers, for each variable appearing in the estimating equations, by year, we treat as missing any observations that are in the extreme top and bottom one percentile (Barth et al., 1999, 2005; Collins, Maydew, \& Weiss, 1997; Fama \& French, 1998; Kothari \& Zimmerman, 1995). After imposing this requirement but before imposing the ESO data availability requirement on a per share basis, the potential sample size ranges from a low of 446 firmyear observations in 1997 to a high of 467 in 2000. Earnings, equity book value and equity market value data are drawn from the Compustat database, and ESO data are from a database provided to us by Jack Ciesielski of R.G. Associates, Inc.

Tables 2 and 3 present sample descriptive statistics and correlations. Table 2 reveals that, on average, equity market value $(M V E)$ far exceeds reported equity book value $\left(B V^{1}\right)$. In fact, untabulated results indicate that the mean (median) market-to-book ratio is 5.4 (3.6). In addition, mean and median residual income for the APB 25 method $\left(R I^{1}\right)$ is positive under both methods of calculating residual income. Although the positive median residual income contrasts with findings in prior research, e.g., Barth et al. (1999), that earlier study's sample period ends in 1997-our first sample year-and the remaining sample years were highly profitable for large U.S. firms. The sample mean and median amounts for the option liability, OPTIONLIAB, are of the same order of magnitude as residual income. As expected for unscaled data, Table 3 reveals significant correlations between many variables.

Table 4 presents regression summary statistics corresponding to the firststage equity valuation equation used to estimate predicted stock prices used as inputs to estimate of ESO fair values using the Black-Scholes model, as described in Section 2.4. Table 4 reveals that the explanatory power of equity book value and residual income is significant and high in every sample year. On the basis of Table 4, we conclude that the first-stage regressions are well-specified. ${ }^{31}$

\section{Empirical results}

\subsection{Comparison of methods based on out-of-sample equity value predictions}

Table 5 presents findings relating to the nested model comparisons. Panel A presents the mean regression summary statistics from the 1,354 and 1,204 jackknife valuation equation estimates based on each of the four ESO accounting methods, i.e. Eqs. (22), (23a-c). Panel B compares out-of-sample prediction accuracy metrics for the four accounting methods. Our discussion focuses on the mean values of squared (MeanSE) and absolute (MeanAE) prediction

\footnotetext{
${ }^{31}$ Note the larger sample sizes for Table 4 estimations relative to the 1,354 and 1,204 firm-year observations used for cross-accounting method comparisons in Tables 5 and 6 reflects the fact that Table 4 only requires data needed to estimate Eq. (23a) for Method 1, the APB 25 method.
} 
Table 2 Descriptive statistics for equity market value, equity book values, residual incomes, and option value-based variables, for a sample of S\&P 500 firms, with 1,354 firm year observations, 1997-2001

\begin{tabular}{lrrr}
\hline Variable & \multicolumn{1}{c}{ Mean } & Median & Std. Dev. \\
\hline$M V E$ & $17,592.90$ & $7,370.68$ & $31,256.90$ \\
$B V^{1}$ & $3,573.59$ & $2,001.14$ & $4,647.57$ \\
$R I^{1}$ & 237.79 & 91.58 & 670.49 \\
$R I^{1}($ FSCC $)$ & 253.98 & 102.72 & 651.59 \\
OPTIONEXPENSE & 41.74 & 17.19 & 82.73 \\
OPTIONLIAB & 180.51 & 117.71 & 218.46 \\
DOPTIONLIAB & -6.93 & 2.85 & 175.43 \\
$r \times$ OPTIONLIAB & 20.67 & 12.94 & 29.27 \\
NETESO & 233.33 & 92.62 & 472.64 \\
$r \times$ NETESO & 18.90 & 7.37 & 37.70 \\
\hline
\end{tabular}

Variable definitions (in \$ million): $M V E=$ market value of common shares outstanding at fiscal year-end; $B V^{1}=$ book value of common equity as of fiscal year-end; $R I^{1}=$ abnormal earnings measured as net income before extraordinary items and discontinued operations, minus 0.12 times $B V^{1}$ (lagged one year); $R I^{1}(F S C C)=$ abnormal earnings measured as net income before extraordinary items and discontinued operations, minus estimated firm-specific cost of capital times $B V^{1}$ (lagged one year). Firm-specific cost of capital is estimated as $r_{f}+\beta \times 0.06$, where $\beta$ is CAPM beta obtained from ValueLine, $r_{f}$ is the prevailing 3-month t-bill rate at the beginning of each fiscal year, and 0.06 is an estimate of the market risk premium, $r_{m}-r_{f}$. The additional data requirement for ValueLine beta reduces the sample size to 1,204 firm-year observations; OPTIONEXPENSE = option expense measured as reported net income minus pro forma net income per SFAS No. 123 disclosure; OPTIONLIAB = fair value of options outstanding at fiscal year-end, measured as the number of options outstanding at fiscal year-end times the estimated year-end fair value per option. The fair value per option is estimated using the Black-Scholes option pricing model. To control for the endogeneity noted by Aboody (1996), predicted prices from a first-stage regression of a benchmark Ohlson model (on a per share basis) is employed in the fair value estimation; The detailed estimation procedure is described in Section 2.4; $D O P T I O N L I A B=O P T I O N L I A B_{t}-O P T I O N L I A B_{t-1}$, a gain or loss item resulting from changes in the fair value of OPTIONLIAB during yeart; $r \times O P T I O N L I A B=0.12$ times OPTIONLIAB (lagged one year), the interest charge associated with OPTIONLIAB; NETESO $=$ The value of ESOs grants summed since 1995, minus OPTIONEXPENSE accumulated since 1995; and $r \times$ NETESO $=0.12$ times NETESO (lagged one year), the interest charge associated with NETESO

errors and their differences across accounting methods. However, we also report corresponding metrics based on median squared (MedSE) and absolute (MedAE) prediction errors. The median accuracy metrics are consistent with, and even reinforce, the inferences drawn from the mean metrics. Panel $\mathrm{C}$ tabulates t-statistics based on pairwise comparisons of the mean squared and absolute errors statistics between methods. Panels D and E tabulate, respectively, the frequency with which each model yields the lowest forecast errors-the "pure horse race" results—and the average rank results.

Beginning with panel A and focusing on the constant cost of capital sample, the mean coefficient on $R I^{1}\left(\alpha_{1}\right)$ ranges from 18.83 under Method 4 to 23.06 under Method 1. These residual income multiples are slightly higher than those reported in Bell et al. (2002), but of a similar order of magnitude. Likewise, the mean $B V^{1}$ coefficients $\left(\alpha_{6}\right)$ range from 2.92 for Methods 2 and 3 to 3.36 for Method 4, and are of similar magnitude to those reported in Bell et al. (2002). As in Bell et al. (2002), the mean coefficients on 


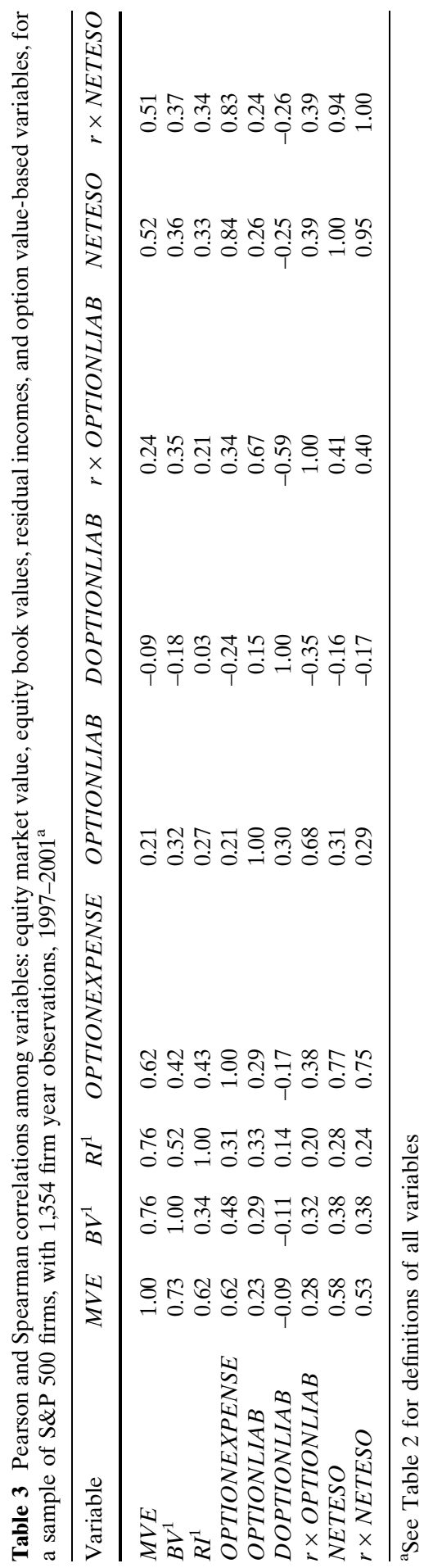




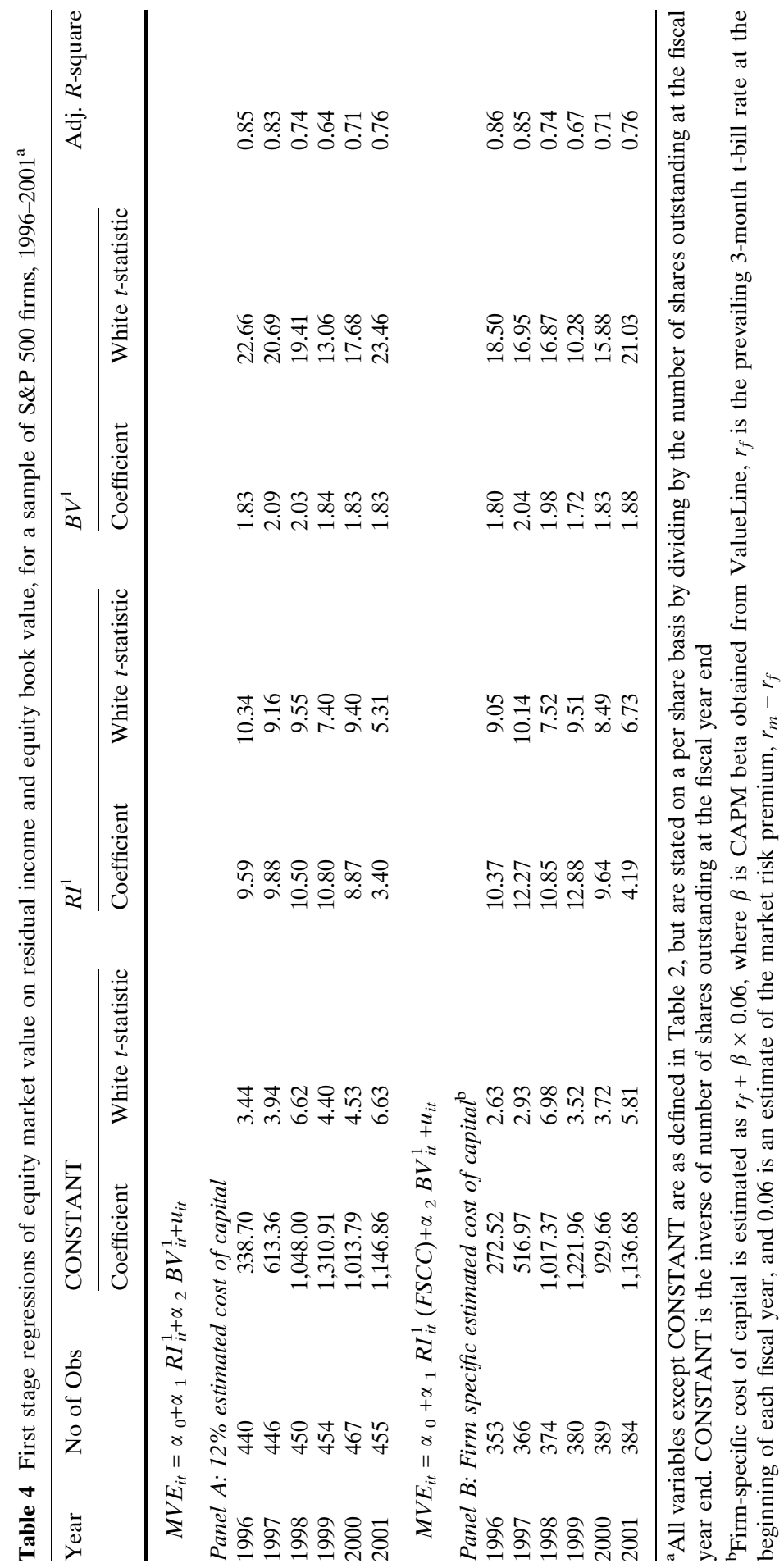




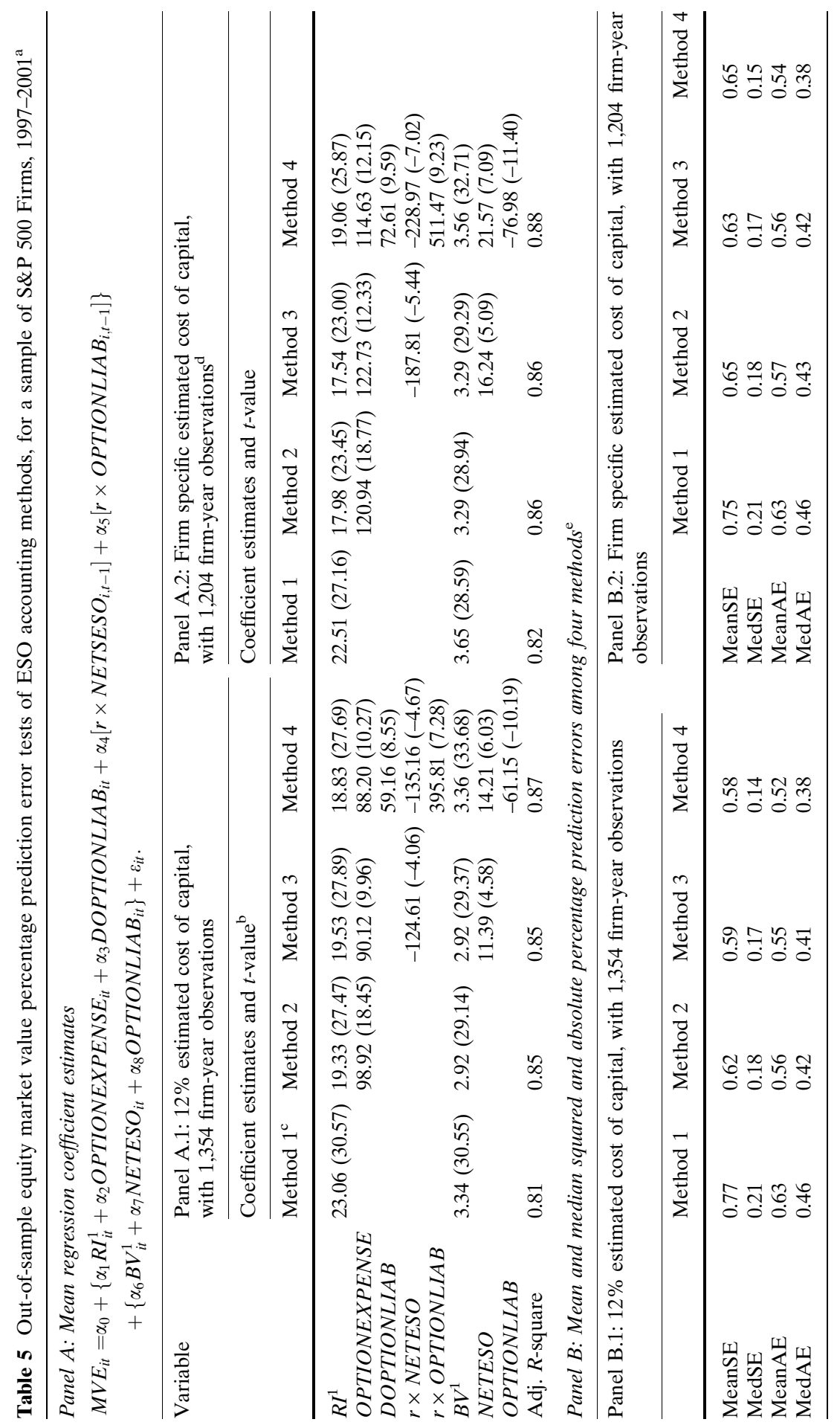




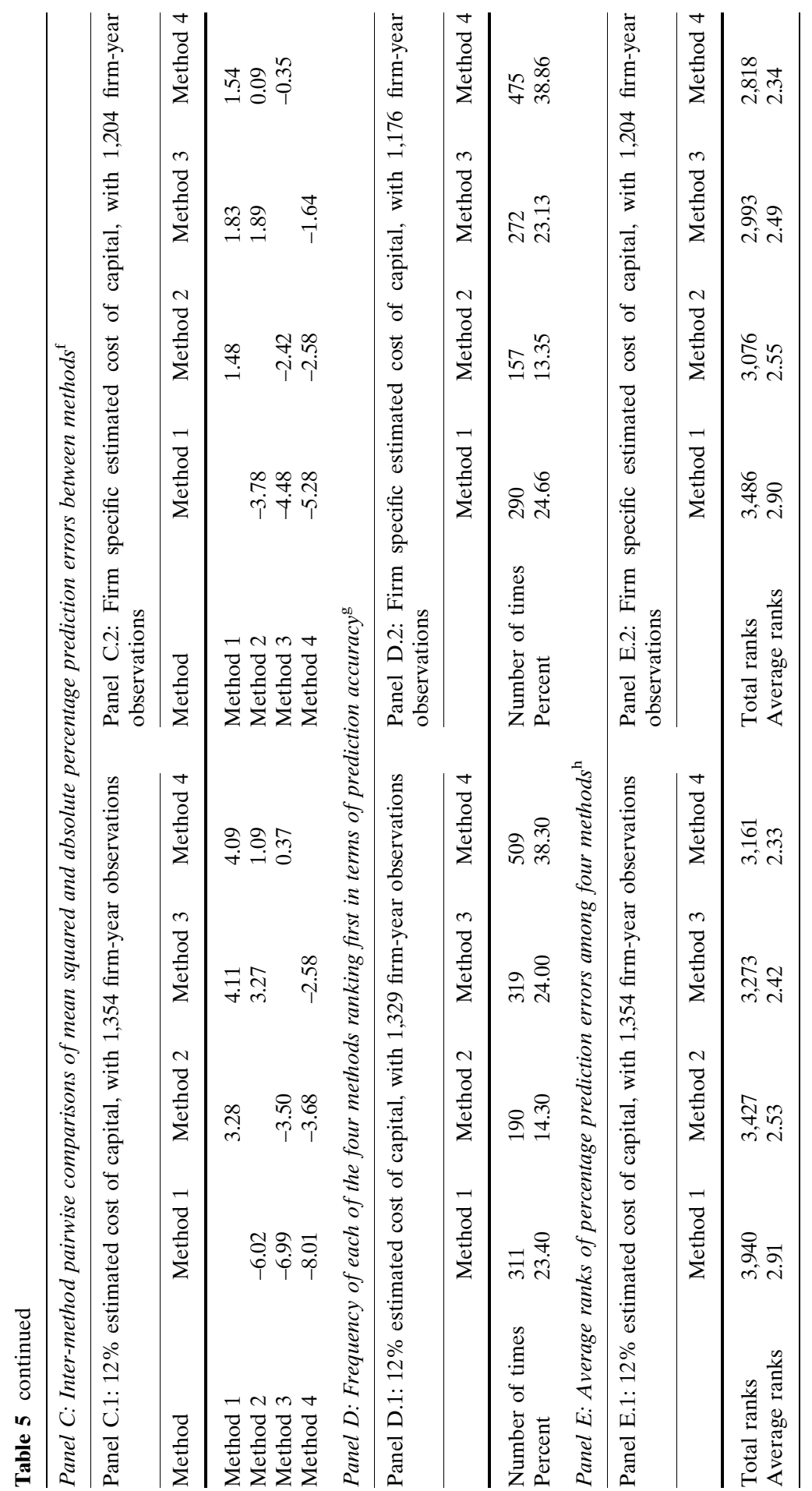




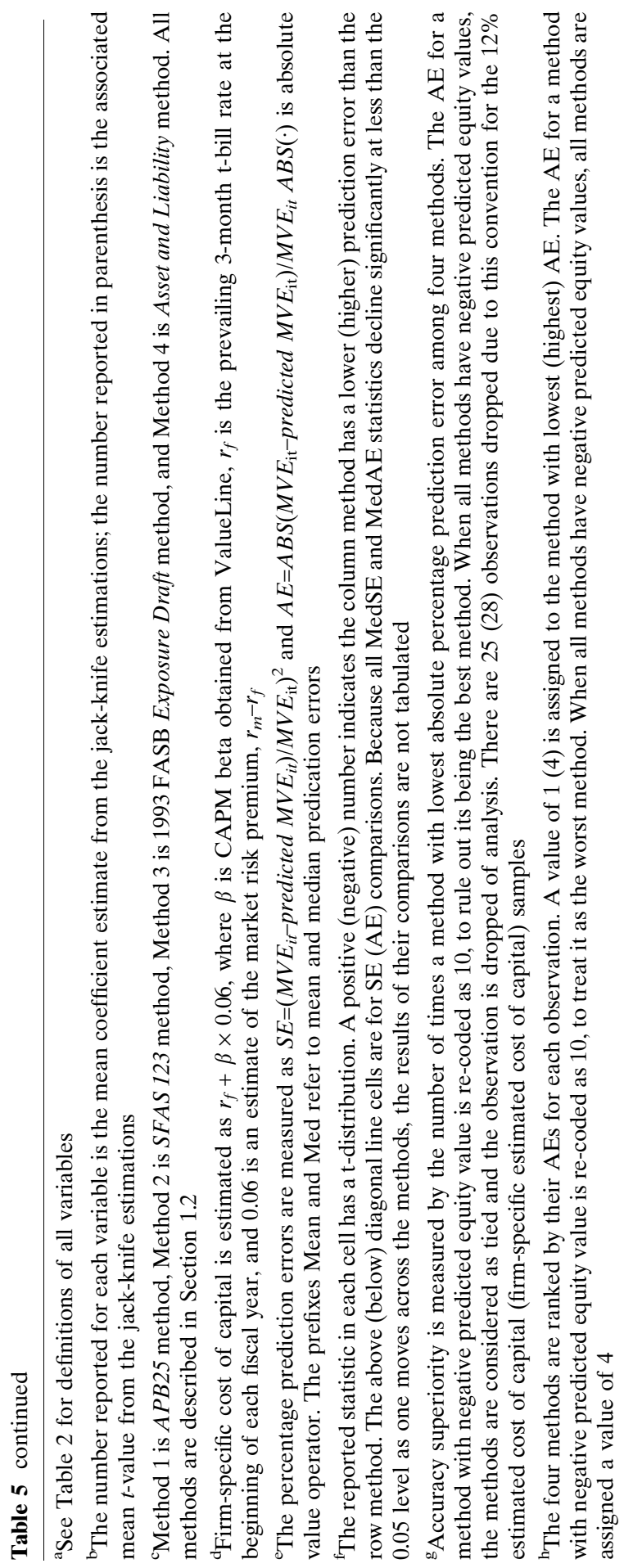


OPTIONEXPENSE $\left(\alpha_{2}\right)$ are positive for each of the three methods in which it appears. For Method 2, this finding is consistent with ESO expense serving as a proxy for the unamortized option asset. For Methods 3 and 4, when the unamortized option asset is included and measured as NETESO, the positive mean OPTIONEXPENSE coefficients suggest that the option asset is measured with error. The mean coefficient on DOPTIOLIAB $\left(\alpha_{3}\right)$ is also positive, and thus appears to be similarly affected by measurement error in the option asset. Regarding the option asset, NETESO, as expected, its mean coefficient $\left(\alpha_{7}\right)$ is positive. The mean coefficient for the capital charge on the option asset $\left(\alpha_{4}\right), r \times N E T E S O$, is negative, as expected. The mean coefficient for the capital charge on the option liability $\left(\alpha_{5}\right), r \times O P T I O N L I A B$, is positive, which is also as expected. Finally, the mean coefficient on OPTIONLIAB $\left(\alpha_{8}\right)$ is negative, as expected. In unreported results we consider the robustness of these estimates to scaling by deflating all variables by (i) sales in period $t$, and (ii) total assets at time $t$. We find that although the magnitudes of coefficients change with deflation, all the main inferences concerning the sign and significance of coefficients remain intact. ${ }^{32}$ Nevertheless, we caution against placing too much weight on the signs and magnitudes of the coefficients, given that Table 3 reveals significant correlations between variables such as $O P T I O N L I A B$ and $r \times O P T I O N L I A B$ (lagged one year).

Panel $\mathrm{B}$ of Table 5 reports the prediction accuracy metrics for each ESO accounting method and panel $\mathrm{C}$ reports the results of significance tests of the differences in prediction accuracy in panel B, using $t$-statistics based on pairwise comparisons of MeanSEs and MeanAEs across the four methods. ${ }^{33}$ The $t$-statistics above (below) the main diagonal pertain to MeanSE (MeanAE) statistics, where a positive (negative) sign indicates the method on the horizontal axis has a lower (higher) error metric. Panel $\mathrm{C}$ does not tabulate analogous statistics based on pairwise comparisons of MedSEs and MedAEs across the four methods because the monotonic decline in panel B from Method 1 to Method 4 is statistically significant at less than the 0.05 level for both the constant and firm-specific cost of capital samples.

The prediction accuracy statistics in panel B.1 indicate that the magnitude of prediction errors decreases with the level of disaggregation. There is a monotonic decline from 0.77 to 0.58 in MeanSE, and from 0.63 to 0.52 in MeanAE as one moves from Method 1 to Method 4. The corresponding panel C.1 indicates that most of these differences in prediction accuracy are statistically significant-only the pairwise comparisons of MeanSE between Methods 4 and 3 and between Methods 4 and 2 are not statistically significant. These differences are consistent with results in panel A indicating that disaggregated accounting components are statistically significant when added in successive models. The results are largely consistent with ESO accounting Method 4 being associated with the highest prediction accuracy for all

\footnotetext{
32 Details are available from the authors on request.

${ }^{33}$ We consider $t$-statistics with associated two-sided $p$-values less than 0.05 as statistically significant.
} 
accuracy metrics reported in panel B.1. Note that median accuracy metrics in panel B.1 are consistent with the mean accuracy metrics, and as noted above all pairwise comparisons of MedSE and MedAS are statistically significant. Results based on firm-specific cost of equity estimates in panels B.2 and C.2 indicate that MeanSE prediction accuracy metrics are mainly consistent with panel B.1, but differences between methods are not statistically significant. One notable difference is the increase in MeanSE moving from Method 3 to Method 4. However, differences in MeanAE, MedSE, and MedAE metrics are entirely consistent with panel B.1 and confirm the superiority of Method $4 .{ }^{34}$

The pure horse race results in panels D.1 and D.2 indicate that Method 4 is the clear winner, with the lowest prediction errors over 38 percent of the time. Methods 1 and 3 have essentially the same performance, with lowest prediction errors 23-24 percent of the time, followed by Method 2, with lowest prediction errors only 13-14 percent of the time. This finding is consistent with Method 4's super-clean surplus accounting being the most frequently accurate model, followed by the two mixed-clean surplus models. Interestingly, the poorest performing model is Method 2, the SFAS 123 (modified) approach, which is the accounting method mandated by both the FASB and the IASB. Turning lastly to the average rank statistics in panels E.1 and E.2, the findings show a monotonic decrease in average ranks as one moves from Method 1 to Method 4. This finding is consistent with the findings in panels B.1 and B.2, which indicate that the magnitude of median prediction errors decreases with the level of additional ESO items included in the estimating equations.

Taken together, the mean and median prediction error findings in Table 5 suggest that Method 1, the $A P B 25$ "do nothing" method, yields the worst equity valuation prediction errors. Of the three methods that include some form of ESO recognition in accounting numbers, the findings suggest that market pricing is more consistent with the recognition of an asset at grant date, since Methods 3 and 4 yield lower prediction errors than gradual expense recognition under Method 2. The results are mixed concerning whether market pricing is consistent with the balance sheet credit being treated as equity (Method 3) or a liability with subsequent marking to market (Method 4), although the weight of the evidence is more supportive of Method 4. However, the statistics focusing on the frequency with which a particular accounting method yields the lowest prediction errors and the average prediction error ranks indicate clear superiority for Method 4.

\subsection{In-sample tests}

The evidence presented above relates to out-of-sample equity market value predictive-ability of the four ESO accounting methods. In this section we adopt an alternative procedure to assess the consistency between the different

\footnotetext{
${ }^{34}$ Inferences based on estimations in which sales and total assets are used as deflators are similar to those based on the reported findings in Table 5.
} 
accounting methods and market pricing, based on in-sample estimation. Although in-sample estimation can be affected by model overfitting (Barth et al., 2005), it can provide additional insights regarding the relevance of accounting numbers under the ESO accounting for market pricing. In particular, in-sample evidence can provide insights into the sources of the out-ofsample results.

In developing our in-sample design, we note that the theoretical residual income valuation models in Section 1 suggest that for Methods 1 and 3, equity book value and residual income explain the combined value of current equity claims and ESOs. This suggests that ESO value should be subtracted from the right hand side in models where current equity value is the dependent variable. The analogous adjustment for Method 2 is more complex, because our theoretical analysis indicates that equity book value and residual income explain equity market value plus a fraction of ESO value. In contrast, because equity book value and residual income explain the market value of current equity claims in Method 4, no adjustment for ESO value should be necessary.

We compare the in-sample ability of the four accounting methods to explain equity value using two sets of tests. First, we estimate valuation equations including equity book value and residual income corresponding to each ESO accounting Method 1 through 4 respectively and test the explanatory power of each of these equations against identical equations in which the option liability, OPTIONLIAB, is included as a regressor, with its coefficient restricted to have a value of minus one (equivalent to transforming the dependent variable to be the market value of current equity plus ESO fair value). Second, we compare the relative explanatory power of the different accounting method models, both with and without controlling for OPTION$L I A B$. We compare relative explanatory power across nested models using Ftests. We test differences in the explanatory power of non-nested models using the Vuong (1989) likelihood ratio test. We estimate all models including year fixed-effects.

Based on the analysis in Section 1.4, we expect that the models for Methods 1 and 3 will be better specified after controlling for OPTIONLIAB, but not for Method 4. Theory provides no clear prediction for Method 2. As with the out-of-sample design, inferences from the in-sample estimates are based on a maintained hypothesis that the included accounting numbers in a model are sufficient to capture expectations of all future residual income realizations. We predict that the estimating equation based on Method 2 should be dominated by each of the other three methods, appropriately adjusted for $O P T I O N L I A B$. This prediction is based on the earlier analysis showing that gradual recognition of equity under Method 2 gives rise to measures of equity book value and residual income that, if used in RIV, are uninformative for estimating either the market value of current equity or the market value of current equity plus ESO value.

Table 6 summarizes the findings from the in-sample tests. Panel A presents the $F$-statistics corresponding to the comparisons of model explanatory power for equations that do or do not include OPTIONLIAB as a regressor. Using a 


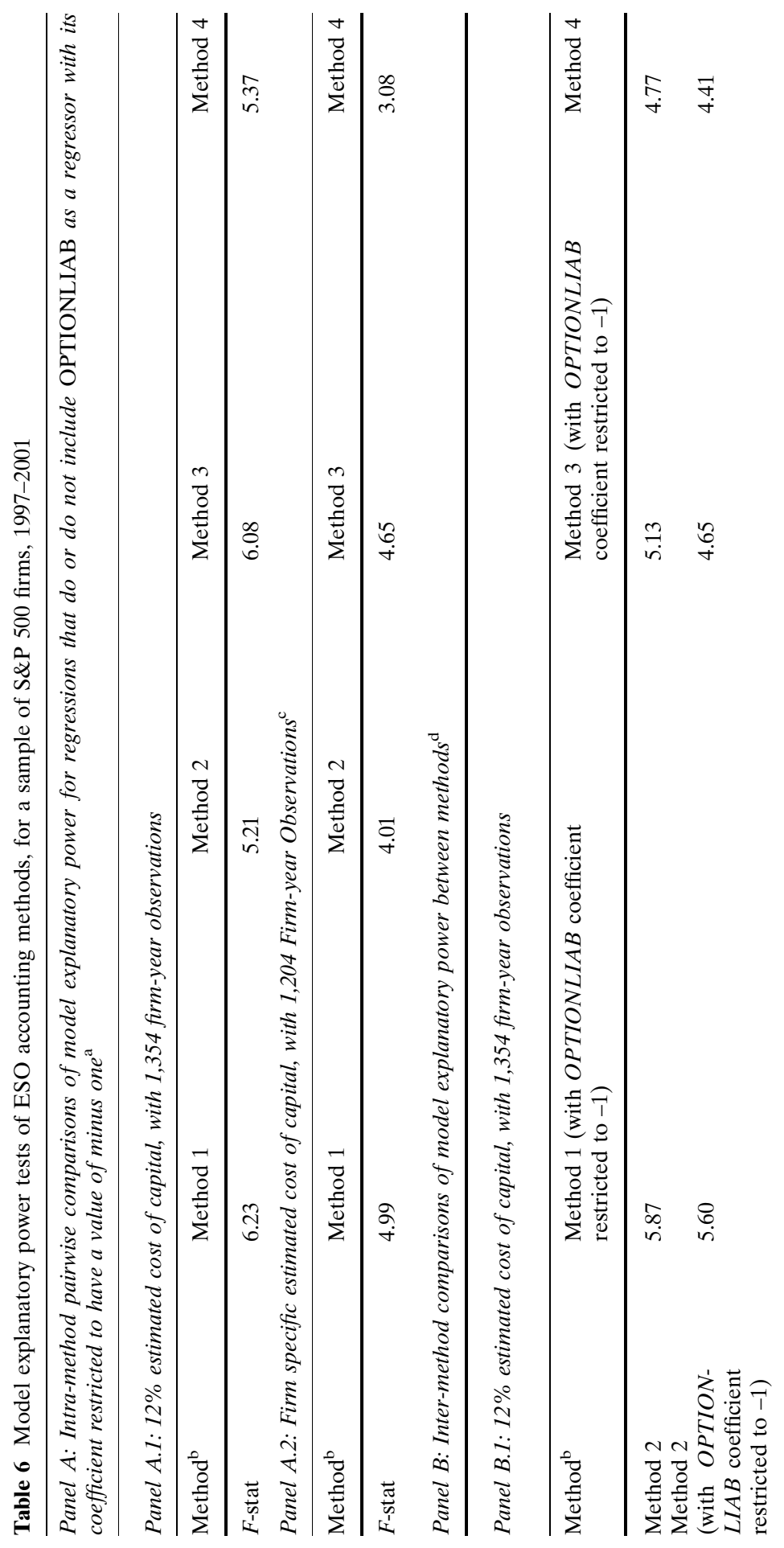




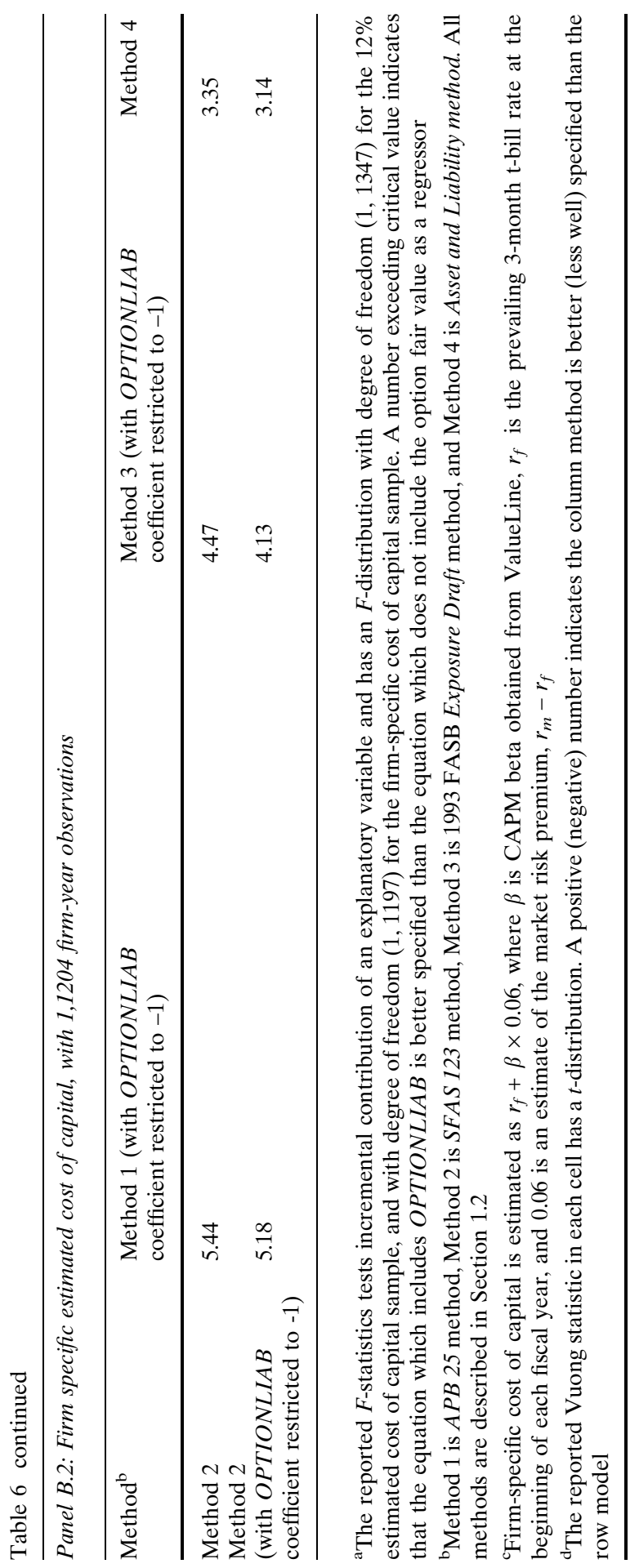


$5 \%$ significance level, we can reject the null of equivalence in model explanatory power for $F$-statistics exceeding 3.84. Panel A.1 indicates that when a constant cost of equity is assumed in estimating residual income, models for all methods appear to be better specified when OPTIONLIAB is included as a regressor with the coefficient restricted to be minus one. These results are consistent with our predictions for Methods 1 and 3, but not for Method 4. Although we have no predictions for Method 2, the $F$-statistic of 5.21 suggests that the model that includes OPTIONLIAB is better specified.

The results in panel A.2 are based on firm-specific cost of equity estimates. These results are consistent with our predictions. Specifically, while models for Methods 1 and 3 are better specified when OPTIONLIAB is included as a regressor, the explanatory power of the model for Method 4 is not improved. This is consistent with (the components of) book equity value and residual income measured under Method 4 being relevant in pricing current equity claims alone.

Table 6, panel B presents the Vuong $t$-statistics corresponding to the comparisons of explanatory power of two versions of Method 2 (both with and without controls for OPTIONLIAB) with each of the other three methods. It reveals that, as predicted, Methods 1, 3, and 4 are better specified than both Method 2 models-the Vuong $t$-statistics are all statistically significant at the $5 \%$ level.

We caution that the results reported in Table 6 might be scale-dependent. Un-tabulated results of tests where we deflate by total assets and sales indicate that the estimates with a restricted $O P T I O N L I A B$ variable are generally not better specified for all methods and that Method 4 is worse-specified, as predicted by theory. Further, tests based on deflated variables confirm the results in Table 6, panel B. Consistent with the reported results, the deflated tests show that Method 2 is dominated by all other three methods.

Collectively, the in-sample findings in Table 6 complement the out-ofsample findings in Table 5. In particular, the evidence in Table 5 suggests that Method 1, the $A P B 25$ "do nothing" method, yields the worst equity valuation prediction errors. It also suggests that of the other three methods involving ESO expense recognition, the methods that also recognize an ESO asset at grant date, i.e. Methods 3 and 4, yield lower prediction errors than Method 2. In summary, the findings in Table 6 support those in Table 5 by indicating that Methods 3 and 4 are better specified than Method 2.

\section{Summary and concluding remarks}

We use the residual income valuation framework to compare the extent to which four approaches to accounting for ESOs, reflecting variations of current and proposed accounting standards, best capture the economic effects of ESOs on current equity market value. We explicitly model the dilution effects on shareholder value of ESOs using the dividend discount model and then use the residual income valuation framework to derive the implied equity values 
associated with each ESO accounting method. Findings from the theoretical modeling indicate that recognized accounting amounts accurately reflect the economic dilution effects of ESOs on current shareholder equity value only when an ESO asset and liability are recognized at grant date, and subsequent gains or losses on the liability are recognized in income. This Asset and Liability method is the only approach that employs super clean surplus accounting, whereby income reflects all gains and losses attributable to existing shareholders. The other accounting methods we consider all result in balance sheet and net income amounts that, when used in the residual income model, overstate the value of current shareholder equity. Specifically, the $A P B 25$ and Exposure Draft methods result in accounting numbers that (when used in valuation) reflect the sum of current shareholder equity value and ESO value. The SFAS 123 accounting method generates accounting numbers that when used in valuation reflect the sum of current shareholder equity value and a fraction of ESO value. This is a troubling result because the SFAS 123 method is the approach mandated by the leading standard setting bodies. Yet it requires financial statement users to make difficult adjustments to accounting numbers if they are to value current equity. We show that the source of the problem is that SFAS 123 is the only one of the four methods that uses dirty surplus accounting, and this occurs because the recognition of ESO expense under SFAS 123 involves the amortization of an off-balance sheet ESO asset.

We use out-of-sample and in-sample tests to assess the value relevance of the four accounting methods. The out-of-sample tests compare contemporaneous equity market value predictions based on each of the four methods. The in-sample tests compare the model explanatory power from two versions of estimating equations relating to each of the four accounting methods. Findings from the out-of-sample tests indicate the Asset and Liability method has the lowest prediction errors, followed by the Exposure Draft method, the SFAS 123 method, and the $A P B 25$ method. Findings from the in-sample tests are largely consistent with our theoretical predictions. The Exposure Draft and the Asset and Liability models appear to be generally better specified than that based on the SFAS 123 (revised) method.

The empirical evidence presented in the study suggests that the $A P B 25$ "do nothing" method is generally inferior to the methods of accounting for ESOs that include some form of ESO recognition, at least when judged in terms of how they are reflected in market pricing. Our evidence also suggests that ESO accounting that does not involve recognition of an asset at grant date-as is the case for IFRS 2 and for the SFAS 123 (revised) method-is likely to be less value relevant. In fact, when measured in terms of frequency of equity market value prediction accuracy superiority, the IFRS 2 and SFAS 123 (revised) accounting methods appear to have lowest value relevance. In addition, our evidence is largely consistent with the superiority of additional grant date recognition of an ESO liability and subsequent marking-to-market of that liability. We caution that these policy conclusions are subject to several important caveats, notably that our theory and empirical tests are based on 
the valuation context and that all the firms in our sample use the $A P B 25$ method. It is impossible to predict the effects on market pricing of ESO accounting amounts once a new standard is adopted because managerial actions could be affected by the imposition of a new ESO accounting method by standard setters.

Acknowledgments The authors are grateful to Jack Ciesielski of R.G. Associates, Inc., for providing the employee stock option data used in this study, and to the Center for Finance and Accounting Research, University of North Carolina, Republic of China National Science Council (Project no. NSC93-2416-H-002-026), and the Financial Services Exchange for providing financial support. The authors thank workshop participants at the 2005 Review of Accounting Studies Conference, particularly David Aboody (discussant) and Jim Ohlson, and the two anonymous reviewers and Stephen Penman, the editor, for helpful comments. The paper also benefited from comments received at the 2004 European Accounting Association Congress, the 2004 London Business School Accounting Symposium, the 2004 University of Minnesota Empirical Accounting Research Conference, Brigham Young University, City University of London, Dartmouth College, University of North Carolina, National Taiwan University, Ohio State University, and Penn State University.

\section{References}

Aboody, D. (1996). Market valuation of employee stock options. Journal of Accounting and Economics, 22, 357-391.

Aboody, D., Barth, M. E., \& Kasznik, R. (2004). SFAS No. 123 stock-based employee compensation and equity market values. The Accounting Review, 79, 251-275.

American Institute of Certified Public Accountants (1972), Accounting Principles Board. Opinion No. 25: Accounting for stock issued to employees. New York NY: AICPA.

Barth, M. E., Beaver, W. H., Hand, J. M., \& Landsman, W. R. (1999). Accruals, cash flows, and equity values. Review of Accounting Studies, 4, 205-229.

Barth, M. E., Beaver, W. H., Hand, J. M., \& Landsman, W. R. (2005). Accruals, accounting-based valuation models, and the prediction of equity values. Journal of Accounting, Auditing, and Finance, 20, 311-345.

Barth, M. E., \& Kallapur, S. (1996). Effects of cross-sectional scale differences on regression results in empirical accounting research. Contemporary Accounting Research, 13, 527-567.

Bell, T. B., Landsman, W. R., Miller, B. L., \& Yeh, S. (2002). The valuation implications of employee stock option accounting for profitable computer software firms. The Accounting Review, 77, 971-996.

Black, F., \& Scholes, M. (1973). The pricing of options and corporate liabilities. Journal of Political Economy, 81(3), 637-654.

Christensen, P. O., \& Feltham, G. A. (2003). Economics of accounting. Volume 1-information in markets. Hingham, MA: Kluwer Academic Publishers.

Collins, D. W., Maydew, E. L., \& Weiss, I. S. (1997). Changes in the value-relevance of earnings \& equity book values over the past forty years. Journal of Accounting and Economics, 24, 39-67.

Core, J., Guay, W., \& Kothari, S. P. (2002). The Economic dilution of employee stock options: Diluted EPS for valuation and financial reporting. The Accounting Review, 77, 627-652.

Credit Suisse First Boston (2004a). Expensing stock options: The impact on S\&P 500 earnings. Accounting \& tax, March. Boston, MA: Credit Suisse.

Credit Suisse First Boston (2004b). Cost of employee stock options. Accounting \& tax, June. Boston, MA: Credit Suisse.

Dechow, P. M., Hutton, A. P., \& Sloan, R. G. (1999). An empirical assessment of the residual income valuation model. Journal of Accounting and Economics, 26, 1-34.

Edwards, E. O., \& Bell, P. W. (1961). The theory and measurement of business income. Berkeley and Los Angeles: University of California Press. 
Fama, E. F., \& French, K. R. (1998). Taxes, financing decisions, and firm value. Journal of Finance, $53,819-843$.

Feltham, G. (1995). Valuation, clean surplus accounting, and anticipated equity transactions. Working paper, University of British Columbia.

Financial Accounting Standards Board (1993). Exposure draft: Accounting for stock-based compensation. Norwalk, CT: FASB.

Financial Accounting Standards Board (1995). Statement of financial accounting standards no. 123: Accounting for stock-based compensation. Norwalk, CT: FASB.

Financial Accounting Standards Board (2004a). Exposure draft: Share based payment. Norwalk CT: FASB.

Financial Accounting Standards Board (2004b). Statement of financial accounting standards no. 123 (revised 2004): Share based payment. Norwalk, CT: FASB

Hand, J. R. M., \& Landsman, W. (2005). The pricing of dividends and equity valuation. Journal of Business Finance and Accounting, 32, 435-469.

Hanlon, M., Rajgopal, S., \& Shevlin, T. (2003). Are executive stock options associated with future earnings? Journal of Accounting and Economics, 36, 3-43.

Hogg, R. V., \& Tanis, E. A. (2001). Probability and statistical inference. Upper Saddle River, NJ: Prentice-Hall.

Ibbotson Associates (2005). Risk premia over time report. Chicago, IL: Ibbotson Associates.

International Accounting Standards Board (2004). International financial reporting standard no. 2: Share-based payment. London: IASB.

Kirschenheiter, M., Mathur, R., \& Thomas, J. K. (2004). Accounting for employee stock options. Accounting Horizons, 18, 135-156.

Kirschenheiter, M., Mathur, R., \& Thomas, J. K. (2005). Entity accounting and dilution: The case of stock options. Working paper, Columbia Business School.

Kothari, S. P., \& Zimmerman, J. (1995). Price and return models. Journal of Accounting and Economics, 20, 155-192.

Li, F., \& Wong, M. H. F. (2005). Employee stock options, equity valuation, and the valuation of option grants using a warrant-pricing model. Journal of Accounting Research, 43, 97-131.

Liu, J., Nissim, D., \& Thomas, J. (1999). Equity valuation using multiples. Journal of Accounting Research, 40, 135-172.

Miller, M. H., \& Modigliani, F. (1961). Dividend policy, growth and the valuation of shares. Journal of Business, 4, 411-433.

Noreen, E. W. (1989). Computer intensive methods for testing hypotheses: An introduction. New York, NY: Wiley.

Ohlson, J. A. (1995). Earnings, equity book values, and dividends in equity valuation. Contemporary Accounting Research, 66-687.

Ohlson, J. A. (1999). On Transitory Earnings. Review of Accounting Studies, 4, 145-162.

Ohlson, J. A., \& Juettnet-Nauroth, B. (2005). Expected EPS and EPS growth as determinants of value. Review of Accounting Studies, 10, 349-365.

Ohlson, J. A., \& Penman S. H. (2005). Debt vs. equity: Accounting for claims contingent on firms' common stock performance with particular attention to employee compensation options. White Paper No. 1, Center for Excellence in Accounting and Security Analysis, Columbia University.

Peasnell, K. V. (1982). Some formal connections between economic values and yields and accounting numbers. Journal of Business Finance and Accounting, 9, 361-381.

Preinreich, G. A. D. (1938). Annual survey of economic theory: The theory of depreciation. Econometrica, 6, 219-241.

Stiglitz, J. E. (2003). The roaring nineties: Seeds of destruction. New York, NY: W. W. Norton \& Company.

Vuong, Q. H. (1989). Likelihood ratio tests for model selection and non-nested hypotheses. Econometrica, 57, 307-333. 